Federal Reserve Bank of Minneapolis

Research Department Staff Report

December 2011

\title{
Gambling for Redemption and Self-Fulfilling Debt Crises*
}

\author{
Juan Carlos Conesa
}

Universitat Autònoma de Barcelona

Timothy J. Kehoe

University of Minnesota, Federal Reserve Bank of Minneapolis, and National Bureau of Economic Research

\begin{abstract}
We develop a model for analyzing the sovereign debt crises of 2010 and 2011 in such European countries as Greece, Ireland, and Portugal. The government sets its expenditure-debt policy optimally given a fixed probability of a recovery in fiscal revenues. In doing so, the government can optimally choose to "gamble for redemption," and the economy can be optimally driven to a level of debt that increases its vulnerability to self-fulfilling debt crises. The model explains why, in contrast to the Mexican crisis of 1994-95, where a loan package put together by U.S. President Bill Clinton put an immediate end to the crisis, rescue packages put together by the European Union do not seem to have ended the crises in Greece, Ireland, or Portugal.
\end{abstract}

Keywords: Euro Zone, debt crisis, slow recovery

JEL codes: F33, F34, F44

* We thank Isabel Correia, David Levine, and Pedro Teles for helpful discussions. We also thank seminar participants at the European University Institute and the Universitat Autònoma de Barcelona. The views expressed herein are those of the authors and not necessarily those of the Federal Reserve Bank of Minneapolis or the Federal Reserve System. 


\section{Introduction}

This paper develops a model of the sorts of sovereign debt crisis that we have witnessed during 2010 and 2011 in such European countries as Greece, Ireland, and Portugal. The government sets its expenditure-debt policy optimally given a fixed probability of a recovery in fiscal revenues. In doing so, the government can optimally choose to "gamble for redemption," and the economy can be optimally driven into a situation of increasing vulnerability to speculative attacks in the form of self-fulfilling debt crises. We provide a theory of sovereign debt crises in which both borrowers and lenders behave optimally, but where countries borrow so much, and lenders are willing to lend them that much, as to make a default unavoidable. Our theory contrasts alternative explanations based on misperceptions or other forms of irrationality.

Our paper provides a benchmark for analyzing government behavior in the face of fiscal pressures and a tool for testing the implications of alternative policy responses. In our analysis, as in Cole and Kehoe (1996, 2000), we characterize in a simple Markov structure the time consistent policy of a strategic government that is faced with non-strategic bond holders.

Figure 1: Debt to GDP ratios in Europe and the United States

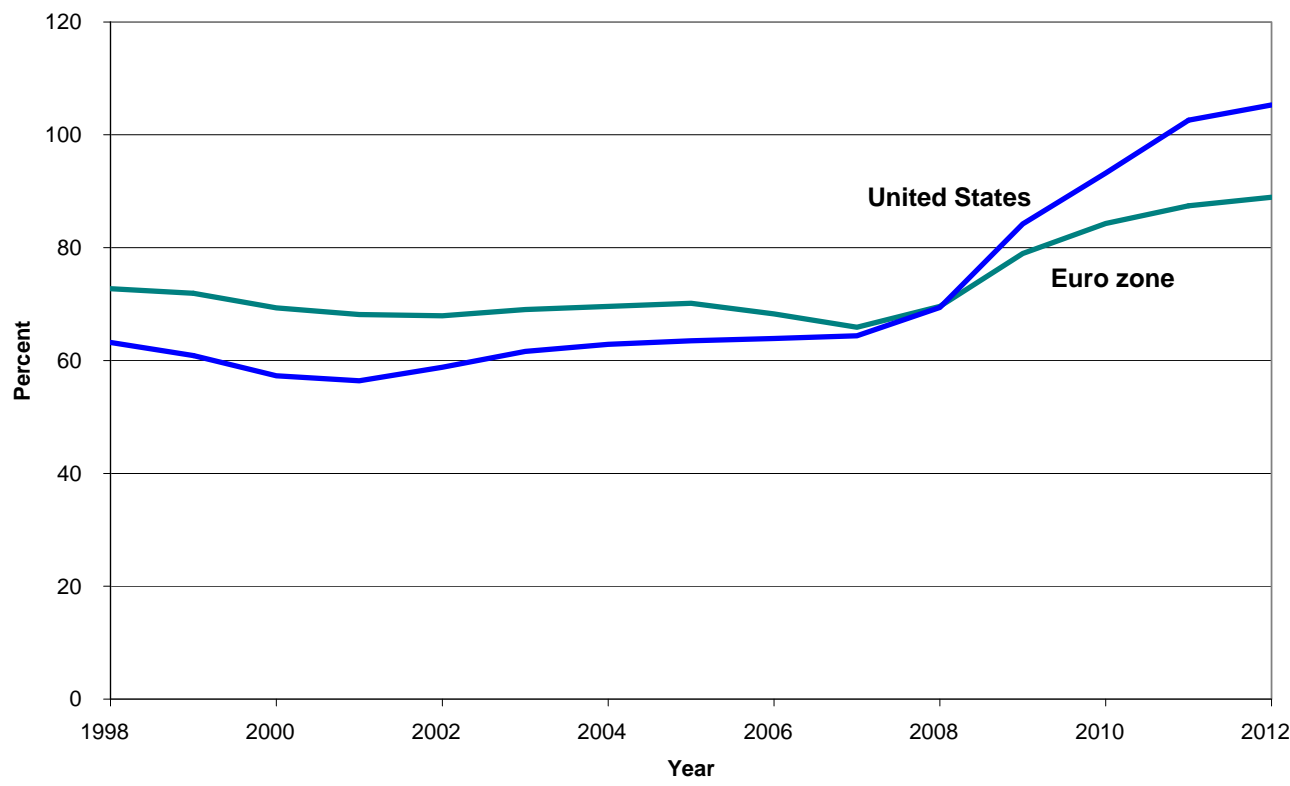

Source: OECD Economic Outlook 2010 for Euro zone data and Economic Report of the President 2011 for U.S. data. 
The recent recession — which continues in many countries — and the policies intended to overcome it have generated very large government budget deficits and increases in government debt over the entire developed world. As Figure 1 shows, in the Unites States debt has gone up since 2001, reaching 93.2 percent of GDP in 2010 and is expected to reach 105.3 percent by 2012, spurring a very heated debate in July 2011 about changing the debt ceiling. In the Euro area the level of government debt was going down systematically since the mid-nineties reaching a minimum in 2007 of 65.9 percent of GDP. Since then, it has grown up to 84.3 percent in 2010 and is expected to reach 88.9 percent in 2012.

The pattern observed for the entire Euro area in Figure 1 is common across most European countries, but it has been more extreme in countries like Greece, whose debt is up to 125.9 percent of GDP in 2010, or to 97.4 percent in Ireland. Figure 2 plots debt to GDP ratios for the most troubled European economies and Germany. Countries like Belgium or Italy, however, have debt to GDP ratios of 98.4 and 119.5 percent respectively. Portugal (with 82.7 percent) is about to enter a rescue package with the same level of debt as France, only slightly below that of Germany.

Figure 2: Debt to GDP ratios in selected European countries

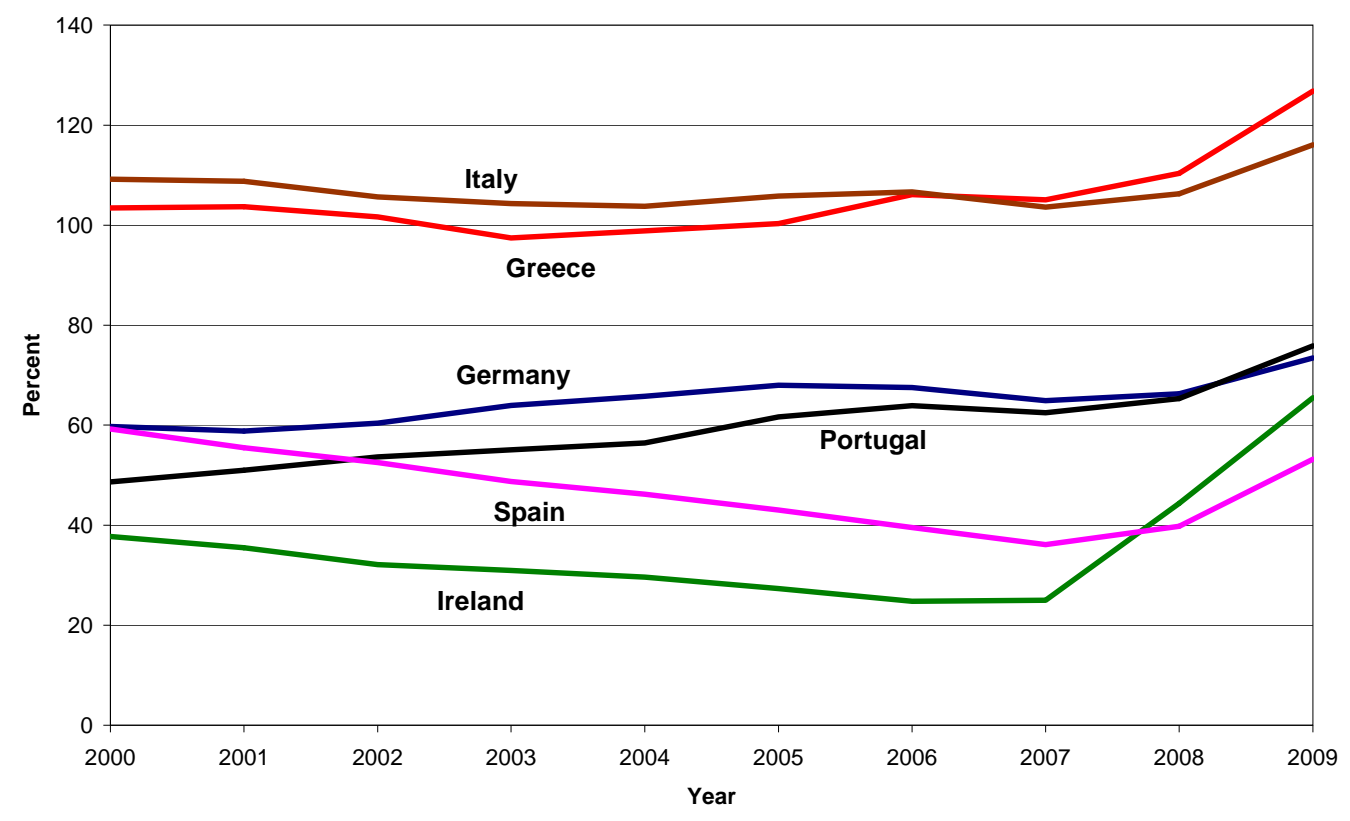

Source: OECD-Stat. 
Looking at figure 2, it is hard to argue that Portugal is subject to more pressures than Germany or that Greece is subject to more pressures than Italy. In the context of our model, the answer is that countries like Greece, Ireland, Portugal and Spain have had budget deficits around 10 percent of GDP, or even more, in 2009 and 2010, while Germany and Italy experienced budget deficits of 3 and 5 percent, respectively. The United States has also experienced these sorts of budget deficits around 10 percent and, until recently, did not appear to be subject to the same sort of pressures. The warning by Standard and Poors on April 18, 2011 that it would downgrade its AAA rating on U.S. government bonds if there is not substantial progress in reducing the U.S. government deficit, however, serves as evidence for the mechanism in our model.

In our model, the crucial element putting countries at risk of suffering a self-fulfilling debt crisis is the drop in government revenues that occurs as the result of a recession in the private sector of the economy. In terms of the fall in government revenues (deflated by the GDP deflator), we observe in figure 3 that Greece, Ireland, and Portugal have all experienced much larger drops that has Germany, but so have Spain and Italy. Our analysis indicates that Spain and Italy are also vulnerable to self-fulfilling crises, and the reason that such crises have not occurred yet in these countries is somewhat arbitrary.

Figure 3: Real government revenues in selected European countries

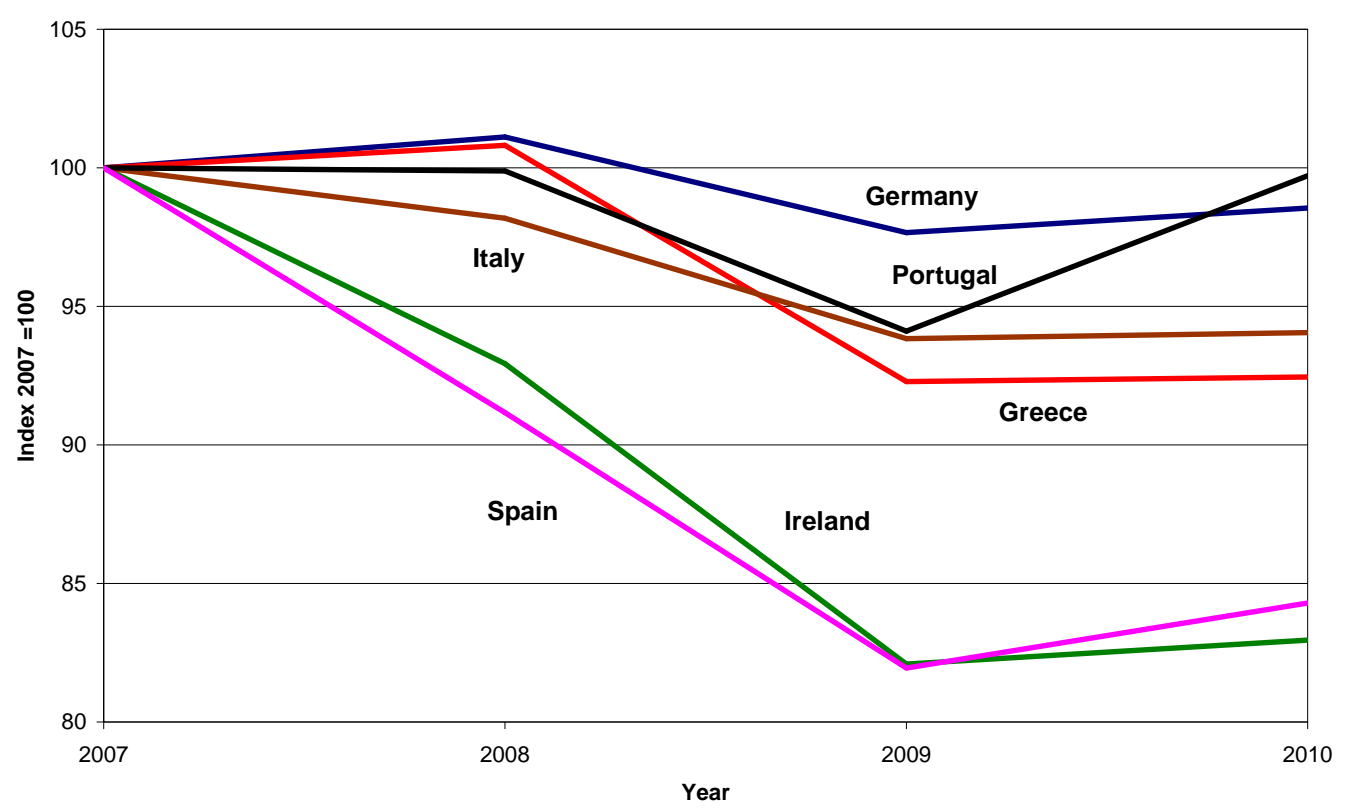




\section{Source: OECD-Stat.}

Our analysis shows that - under certain conditions, which correspond to parameter values in our model — it is optimal for the government to "gamble for redemption." By this, we mean that the government does not undertake painful adjustments to reduce spending, hoping for a recovery of government revenues, and debt continues to increase. Indeed, the government strategy follows a martingale gambling strategy that will send the economy into the crisis zone if the recovery does not happen soon enough. Under other conditions, however, the government gradually reduces the level of debt to exit the crisis zone and avert the possibility of a liquidity crisis, as in Cole and Kehoe (2000).

Notice that in our environment not running down debt (or running it up until default is unavoidable) is part of the optimal strategy under some circumstances. In contrast, in their excellent overview of past default experiences Reinhart and Rogoff (2009) argue that the reason some countries fail to adjust and are vulnerable to a potential crisis is because somehow both the governments and their lenders are fooling themselves into thinking that "this time is different" (this is indeed the title of their book). As such, countries vulnerability would be the result of selfdelusion and lack of rationality. In contrast to their view, we provide a model in which such apparently irrational behavior can be an optimal response to either fundamentals or to expectations of a bailout by both borrowing governments and lenders that perfectly understand the risks of a crisis.

This paper is most related to those of Cole and Kehoe (1996, 2000). Cole and Kehoe provide a dynamic stochastic general equilibrium model of a country subject to the possibility of a self-fulfilling debt crisis in every period. The substantial difference between their framework and ours is that, in their framework, debt crises are liquidity crisis due to solely to the inability to roll over debt that could arise under certain conditions. As such, a decisive action by a third party providing a loan or a bailout would be enough to avert the problem. Indeed, Cole and Kehoe (1996, 2000) intended their model to shed light on the financial troubles of Mexico in 1994-95, and, in that occasion, the decisive action of the Clinton administration on January 31, 1995 was enough to avert the crisis. European Union rescue packages for countries Greece, Ireland, and Portugal have not had the same healing properties. In fact, quite the opposite seems to be the case, with the spreads on bonds, relative to Germany's, continuing to rise despite the 
announcements and first implementations of the rescue packages. This indicates more fundamental solvency problems than those present in a standard liquidity crisis of the type studied in Cole and Kehoe, as discussed by Chamley and Pinto (2011) for the Greek case. Our model accommodates this issue.

Arellano (2008) focuses on default incentives on international borrowing over the cycle, but does not determine the optimal behavior of government finances. Similar frameworks have been used to analyze currency crisis following Calvo (1988).

Our model establishes conditions under which a debt crisis can occur, and how that possibility shapes optimal government's behavior, but is silent about why at a particular point in time a crisis might or might not occur. Indeed, once the government is in the crisis zone (and we show under what conditions a government will find it optimal to enter it) a potential crisis is triggered by a non-fundamental random variable: a sunspot. A very interesting related strand of the literature, starting with the work of Morris and Shin (1998), would relate the probability of such an event happening to lack of perfect knowledge within a global game framework. While this strand of the literature focuses on why a crisis might happen at a particular point in time, we focus on the conditions under which a benevolent government might find it optimal to subject itself to such a vulnerable position.

Bailouts in the form of issuing credit at below market price to troubled economies — as those used in the presence of liquidity crisis - might or might not work. In fact, we develop a calibrated example in which the probability of a bailout makes it more attractive for a government to enter the crisis zone, becoming more vulnerable to a crisis.

Our model provides sharp predictions of when a third party bailout helps avert a liquidity crisis, as in the case of the Mexican crisis of 1994-95, and when such a strategy would only make things worse. Since the response of the government is always optimal, however, the only policy prescription relate to the optimal form of the bailout for the intervening third party. A different scenario arises if the government is impatient, as in Cole and Kehoe (1996), or if the government assigns a different probability to a recovery than bankers, or if the government is trying to trick bankers or third parties capable of implementing a bailout with respect to the probability of a recovery. It might be the case that the government is gambling for redemption, while it should be making sacrifices and decreasing its debt position. A complete analysis of a game between two strategic players - the government of the country and the third party, in the 
case of the European countries that we have discussed, the European Union, or more specifically, Angela Merkel — is beyond the scope of this paper.

\section{General model}

The state of the economy in every period $s=\left(B, a, z_{-1}, \zeta\right)$ is the level of government debt $B$, whether or not the private sector is in normal conditions $a=1$ or in a recession $a=0$, whether or not default has occurred in the past $z_{-1}$, and the value of the sunspot variable $\zeta$.

The country's GDP is

$$
y(a, z)=A^{1-a} Z^{1-z} \bar{y}
$$

where $1>A, Z>0$. Before period $0, a=1, z=1$. In period $0, a$ unexpectedly becomes $a_{0}=0$ and GDP drops from $y=\bar{y}$ to $y=A \bar{y}<\bar{y}$. In every period $t, t=1,2, \ldots, a_{t}$ becomes 1 with probability $p, 1>p>0$. Once $a_{t}=1$, it stays equal to 1 forever. The drop in productivity by the factor $Z$ is the country's default penalty. Once $z_{t}=0$, it stay equal to 0 forever. Here the default penalty occurs in the same period as the crisis. We could have it occur in the next period, in which case

$$
y\left(a, z_{-1}\right)=A^{1-a} Z^{1-z_{-1}} \bar{y} .
$$

While the results in our numerical experiments would change, this alternative assumption has no qualitative effect on our results.

Government tax revenue is $\theta y(a, z)$ where we assume, to keep things simple, that the tax rate $\theta$ is fixed. The government's problem is to choose $c, g, B^{\prime}, z$ to solve

$$
\begin{gathered}
V(s ; p, \pi)=\max u(c, g)+\beta E V\left(s^{\prime} ; p, \pi\right) \\
\text { s.t. } c=(1-\theta) y(a, z) \\
g+z B=\theta y(a, z)+q\left(B^{\prime}, s ; p, \pi\right) B^{\prime} \\
z=0 \text { if } z_{-1}=0 .
\end{gathered}
$$

Here $z=1$ is the decision not to default, and $z=0$ is the decision to default. We later specify the precise timing of the interaction of the government and international bankers, which determines the price of bonds $q\left(B^{\prime}, s ; p, \pi\right)$ and the default decision $z$. 
Some possibilities for $u(c, g)$ are

$$
\begin{gathered}
u(c, g)=(1-\gamma) \log c+\gamma \log g \\
u(c, g)=(1-\gamma) \log c+\gamma \log (g-\bar{g}) \\
u(c, g)=\log (c+g-\bar{c}-\bar{g}),
\end{gathered}
$$

or we could impose even more curvature than that of the natural logarithm. The last specification incorporates the idea that during a recession, when private consumption is low, the government has an incentive to increase public spending. In general, we assume that, for any $b$ such that $A \bar{y}-b$ is an element of the feasible set of levels for government expenditures $g$,

$$
u_{g}((1-\theta) A \bar{y}, \theta A \bar{y}-b)>u_{g}((1-\theta) \bar{y}, \theta \bar{y}-b) .
$$

This assumption provides the government with the incentive to transfer resources into the current period during a recession from future periods in which the economy has recovered. It is satisfied by any concave utility function separable in $c$ and $g$. It is also satisfied by functions like $\log (c+g-\bar{c}-\bar{g})$.

In every period a random variable $\zeta_{t}$ is drawn from the uniform distribution on $[0,1]$. If $\zeta_{t}>1-\pi$, international bankers expect there to be a crisis and do not lend to the government if such a crisis would be self-fulfilling. This allows us to set the probability of a self-fulfilling crisis at an arbitrary level $\pi, 1 \geq \pi \geq 0$, if the level of debt is high enough for such a crisis to be possible. The timing within each period is like that in Cole and Kehoe (1996, 2000):

1. $\zeta_{t}$ is realized, the aggregate state is $s_{t}=\left(B_{t}, a_{t}, z_{t-1}, \zeta_{t}\right)$, and the government chooses how much debt $B_{t+1}$ to sell.

2. Each of a continuum of measure one of international bankers chooses how much debt $b_{t+1}$ to purchase. (In equilibrium, of course, $b_{t+1}=B_{t+1}$.)

3. The government makes it default decision $z_{t}$, which determines $y_{t}, c_{t}$, and $g_{t}$. 
The crucial elements of this timing are that, first, the government chooses how much debt $B_{t+1}$ it wants to sell and this determines the price of the debt if there is no crisis, and only later does the government choose whether to default or not. That is, the price of the debt depends on the amount of new debt being offered $B_{t+1}$, but whether or not a crisis takes place depends on the amount of debt that has to be repaid $B_{t}$.

\subsection{Bond prices}

International bankers are risk neutral with discount factor $\beta$ so that the bond prices $q\left(B^{\prime}, s ; p, \pi\right)$ are determined by the probability of default in the next period. There is a continuum of measure one of bankers. Each solves the dynamic programming problem

$$
\begin{aligned}
W\left(b, B^{\prime}, s ; p, \pi\right) & =\max x+\beta E W\left(\left(b^{\prime}, B^{\prime \prime}, s^{\prime} ; p, \pi\right)\right. \\
x+q\left(B^{\prime}, s ; p, \pi\right) b^{\prime} & =w+z\left(B^{\prime}, s, q\left(B^{\prime}, s ; p, \pi\right) ; p, \pi\right) b \\
x & \geq 0, b \geq-A .
\end{aligned}
$$

The constraint $b \geq-A$ eliminates Ponzi schemes, but $A$ is large enough so that the constraint does not otherwise bind. We assume that the banker's endowment of consumption good $w$ is large enough to rule out corner solutions in equilibrium.

There are four cutoff levels of debt: $\bar{b}(a ; p, \pi), \bar{B}(a ; p, \pi), a=0,1$ :

1. If $B \leq \bar{b}(0 ; p, \pi)$, the government does not default when the private sector is in a recession even if international bankers do not lend, and, if $B>\bar{b}(0 ; p, \pi)$, the government defaults when the private sector is in a recession if international bankers do not lend.

2. If $B \leq \bar{b}(1 ; p, \pi)$, the government does not default when the private sector is in normal conditions even if international bankers do not lend, and, if $B>\bar{b}(1 ; p, \pi)$, the government defaults when the private sector is in normal conditions if international bankers do not lend.

3. If $B \leq \bar{B}(0 ; p, \pi)$, the government does not default when the private sector is in a recession if international bankers lend, and, if $B>\bar{B}(0 ; p, \pi)$, the government defaults when the private sector is in a recession even if international bankers lend. 
4. If $B \leq \bar{B}(1 ; p, \pi)$, the government does not default when the private sector is in a normal conditions if international bankers lend, and, if $B>\bar{B}(1 ; p, \pi)$, the government defaults when the private sector is in normal conditions even if international bankers lend.

The assumption that once $z_{t}=0$, it stay equal to 0 forever says that a country that defaults is permanently excluded from international borrowing or lending. This assumption can be modified at the cost of complicating the analysis. The assumption has two consequences for the relation of the bond price $q$ to the current state $s$ : First, once default has occurred, international bankers do not lend:

$$
q\left(B^{\prime},(B, a, 0, \zeta) ; p, \pi\right)=0 .
$$

Second, during a crisis, international bankers do not lend:

$$
q\left(B^{\prime},(B, a, 1, \zeta) ; p, \pi\right)=0
$$

if $B>\bar{b}(a ; p, \pi)$ and $\zeta>1-\pi$. Otherwise, the bond price $q$ depends on the amount of bonds $B^{\prime}$ that the government offers for sale.

We will show that $\bar{b}(0 ; p, \pi)<\bar{b}(1 ; p, \pi), \bar{b}(0 ; p, \pi)<\bar{B}(0 ; p, \pi), \bar{b}(1 ; p, \pi)<\bar{B}(1 ; p, \pi)$, and $\bar{B}(0 ; p, \pi)<\bar{B}(1 ; p, \pi)$. Here, we first consider the case where $\bar{b}(1 ; p, \pi)<\bar{B}(0 ; p, \pi)$, that is, where

$$
\bar{b}(0 ; p, \pi)<\bar{b}(1 ; p, \pi)<\bar{B}(0 ; p, \pi)<\bar{B}(1 ; p, \pi) .
$$

The first order condition for to the international bankers' utility maximization problem implies that

$$
q\left(B^{\prime}, s ; p, \pi\right)=\beta E z\left(B^{\prime}, s, q\left(B^{\prime}, s ; p, \pi\right) ; p, \pi\right),
$$

which implies that

$$
q\left(B^{\prime},(B, 0,1, \zeta) ; p, \pi\right)= \begin{cases}\beta & \text { if } B^{\prime} \leq \bar{b}(0 ; p, \pi) \\ \beta(p+(1-p)(1-\pi)) & \text { if } \bar{b}(0 ; p, \pi)<B^{\prime} \leq \bar{b}(1 ; p, \pi) \\ \beta(1-\pi) & \text { if } \bar{b}(1 ; p, \pi)<B^{\prime} \leq \bar{B}(0 ; p, \pi) \\ \beta p(1-\pi) & \text { if } \bar{B}(0 ; p, \pi)<B^{\prime} \leq \bar{B}(1 ; p, \pi) \\ 0 & \text { if } \bar{B}(1 ; p, \pi)<B^{\prime}\end{cases}
$$




$$
q\left(B^{\prime},(B, 1,1, \zeta) ; p, \pi\right)=\left\{\begin{array}{l}
\beta \\
\beta(1-\pi) \\
0
\end{array}\right.
$$

if $B^{\prime} \leq \bar{b}(1 ; p, \pi)$

if $\bar{b}(1 ; p, \pi)<B^{\prime} \leq \bar{B}(1 ; p, \pi)$.

if $\bar{B}(1 ; p, \pi)<B^{\prime}$ 
Figure 4: Bond prices as a function of bonds offered for sale and conditions in the private sector

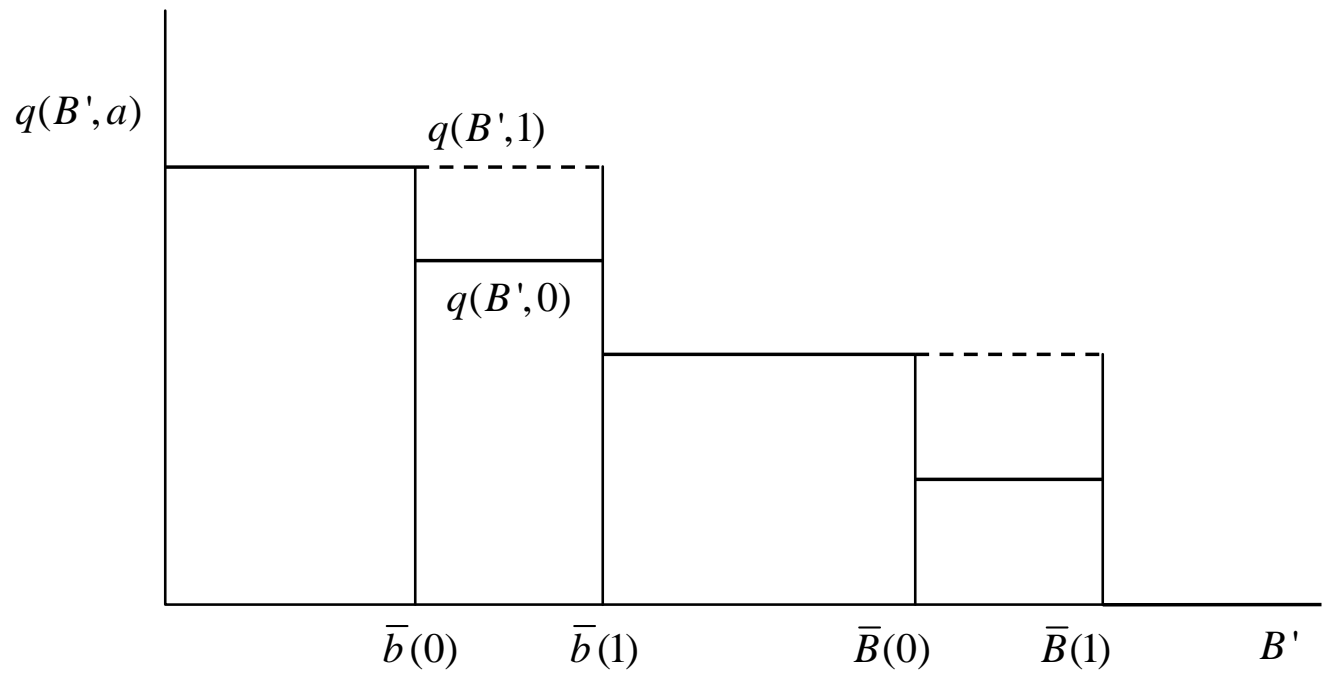

Now consider the case where $\bar{B}(0 ; p, \pi)<\bar{b}(1 ; p, \pi)$, that is, where

$$
\bar{b}(0 ; p, \pi)<\bar{B}(0 ; p, \pi)<\bar{b}(1 ; p, \pi)<\bar{B}(1 ; p, \pi) \text {. }
$$

Here the solution to the international bankers' utility maximization problem implies that

$$
q\left(B^{\prime},(B, 0,1, \zeta) ; p, \pi\right)= \begin{cases}\beta & \text { if } B^{\prime} \leq \bar{b}(0 ; p, \pi) \\ \beta(p+(1-p)(1-\pi)) & \text { if } \bar{b}(0 ; p, \pi)<B^{\prime} \leq \bar{B}(0 ; p, \pi) \\ \beta p & \text { if } \bar{B}(0 ; p, \pi)<B^{\prime} \leq \bar{b}(1 ; p, \pi) \\ \beta p(1-\pi) & \text { if } \bar{b}(1 ; p, \pi)<B^{\prime} \leq \bar{B}(1 ; p, \pi) \\ 0 & \text { if } \bar{B}(1 ; p, \pi)<B^{\prime}\end{cases}
$$

There is yet a third case, which we will show is not degenerate, where

$$
\bar{b}(0 ; p, \pi)<\bar{b}(1 ; p, \pi)=\bar{B}(0 ; p, \pi)<\bar{B}(1 ; p, \pi) .
$$

Here

$$
q\left(B^{\prime},(B, 0,1, \zeta) ; p, \pi\right)=\left\{\begin{array}{ll}
\beta & \text { if } B^{\prime} \leq \bar{b}(0 ; p, \pi) \\
\beta(p+(1-p)(1-\pi)) & \text { if } \bar{b}(0 ; p, \pi)<B^{\prime} \leq \bar{b}(1 ; p, \pi) \\
\beta p(1-\pi) & \text { if } \bar{b}(1 ; p, \pi)<B^{\prime} \leq \bar{B}(1 ; p, \pi) \\
0 & \text { if } \bar{B}(1 ; p, \pi)<B^{\prime}
\end{array} .\right.
$$


Since the second and the third cases, where $\bar{B}(0 ; p, \pi) \leq \bar{b}(1 ; p, \pi)$, are only possible for very low values of $A$, we will focus on the first case.

\subsection{Definition of equilibrium}

An equilibrium is a value function for government $V(s)$ and policy functions $B^{\prime}(s)$ and $z\left(B^{\prime}, s, q ; p, \pi\right)$ and $g\left(B^{\prime}, s, q ; p, \pi\right)$, a value function for bankers $W\left(b, B^{\prime}, s ; p, \pi\right)$ and policy correspondence $b^{\prime}\left(b, B^{\prime}, s ; p, \pi\right)$, and a bond price function $q\left(B^{\prime}, s ; p, \pi\right)$ such that

1. $V(s)$ and $B^{\prime}(s)$ solve the government's problem at the beginning of the period:

$$
\begin{gathered}
V\left(B, a, z_{-1}, \zeta ; p, \pi\right)=\max u(c, g)+\beta E V\left(B^{\prime}, a^{\prime}, z, \zeta^{\prime} ; p, \pi\right) \\
\text { s.t. } c=(1-\theta) y\left(a, z\left(B^{\prime}, s, q\left(B^{\prime}, s ; p, \pi\right) ; p, \pi\right)\right) \\
g\left(B^{\prime}, s, q\left(B^{\prime}, s ; p, \pi\right) ; p, \pi\right)+z\left(B^{\prime}, s, q\left(B^{\prime}, s ; p, \pi\right) ; p, \pi\right) B \\
\quad=\theta y(a, z)+q\left(B^{\prime}, s ; p, \pi\right) B^{\prime}
\end{gathered} .
$$

2. $\quad b^{\prime}\left(b, B^{\prime}, s ; p, \pi\right)$ solves the banker's problem and $q\left(B^{\prime}, s ; p, \pi\right)$ is consistent with market clearing and rational expectations:

$$
\begin{gathered}
B^{\prime}(s) \in b^{\prime}\left(b, B^{\prime}, s ; p, \pi\right) \\
q\left(B^{\prime}, s ; p, \pi\right)=\beta E z\left(B^{\prime}, s, q\left(B^{\prime}, s ; p, \pi\right) ; p, \pi\right) .
\end{gathered}
$$

3. $z\left(B^{\prime}, s, q ; p, \pi\right)$ and $g\left(B^{\prime}, s, q ; p, \pi\right)$ solve the government's problem at the end of the period:

$$
\begin{gathered}
\max u(c, g)+\beta E V\left(B^{\prime}, a^{\prime}, z, \zeta^{\prime} ; p, \pi\right) \\
\text { s.t. } c=(1-\theta) y(a, z) \\
g+z B=\theta y(a, z)+q B^{\prime} \\
z=0 \text { or } z=1, \text { but } z=0 \text { if } z_{-1}=0 .
\end{gathered}
$$

Notice that, when the government solves its problem at the beginning of the period, it takes as given the optimal responses both of international bankers and itself later in the period. In particular, the government cannot commit to repaying its debt and not defaulting later in the period. Furthermore, since the occurrence of a crisis depends on the amount of debt to be repaid $B$, not the amount of debt offered for sale $B^{\prime}$, once a sunspot has occurred that signals that a 
self-fulfilling crisis will take place that period, there is nothing that the government can do to avoid it.

It is also worth noting that this model has many equilibria. Our definition of equilibrium restricts our attention to equilibria with a simple Markov structure. Many other possibilities are possible. If we include the date in the state $s=\left(B, a, z_{-1}, \zeta, t\right)$, for example, we could allow crises to occur only in even periods $t$ or in periods that are prime numbers, or we could allow the probability of a crisis $\pi$ to be time varying in other ways. The advantage of our simple Markov structure is that it makes it easy to characterize and compute equilibria.

\section{Self-fulfilling liquidity crises}

Although we are able to prove some propositions about the equilibria of the general model, we need to resort to numerical examples to illustrate the possibilities and to do comparative statics analysis. Before turning to the results for the general model, we study two special cases, where we can provide analytical characterizations of the equilibria in which we are interested. The first is the case where $a=1$, that is, where the private sector has recovered and where there is no incentive for the government to gamble for redemption. This is the model of Cole-Kehoe (1996, 2000) without private capital. Notice that we can easily modify the analysis of this case to study the limiting case where $a=0$ and $p=0$, that is, where there is a recession but no possibility for recovery, simply by replacing $\bar{y}$ with $A \bar{y}$ in what follows. In this case, where self-fulfilling crises are possible, but where there is no incentive for the government to gamble for redemption, the optimal strategies of the government involve either leaving debt constant or running it down to eliminate the possibility of a crisis. In the next section, we consider the other extreme case, where recovery is possible but not self-fulfilling crises.

We start by assuming that $\pi=0$. Notice that, since a recovery has already occurred in the private sector, $p$ is irrelevant. To derive the optimal government policy, we solve

$$
\begin{gathered}
\max \sum_{t^{\prime}=t}^{\infty} \beta^{s} u\left(c_{t^{\prime}}, g_{t^{\prime}}\right) \\
\text { s.t. } c_{t^{\prime}}=(1-\theta) \bar{y} \\
g_{t^{\prime}}+B_{t^{\prime}}=\theta \bar{y}+\beta B_{t^{\prime}+1} \\
B_{t^{\prime}}=B
\end{gathered}
$$




$$
B_{t^{\prime}} \leq \bar{B}(1 ; p, 0)
$$

The first order conditions are

$$
\begin{gathered}
\beta^{t^{\prime}} u_{g}\left((1-\theta) \bar{y}, g_{t^{\prime}}\right)=\lambda_{t^{\prime}} \\
\lambda_{t^{\prime}+1}=\beta \lambda_{t^{\prime}} .
\end{gathered}
$$

The transversality condition is

$$
\lim _{t^{\prime} \rightarrow \infty} \lambda_{s} B_{t^{\prime}+1} \geq 0
$$

The first order conditions imply that

$$
\begin{gathered}
u_{g}\left((1-\theta) \bar{y}, g_{t^{\prime}}\right)=u_{g}\left((1-\theta) \bar{y}, g_{t^{\prime}-1}\right) \\
g_{t^{\prime}+1}=g_{t^{\prime}}=\hat{g}
\end{gathered}
$$

Consequently,

$$
B_{t^{\prime}+1}=\frac{1}{\beta}\left(\hat{g}+B_{t^{\prime}}-\theta \bar{y}\right) .
$$

Suppose that

$$
\hat{g}=\theta \bar{y}-(1-\beta) B
$$

Then $B_{s}=B$. Otherwise $B_{t^{\prime}}$ is explosive. It is easy to show that too low of a $\hat{g}$ results in a path for $B_{t^{\prime}}$ that violates the transversality condition. Too high of a $\hat{g}$ results in a path for $B_{t^{\prime}}$ that hits $\bar{B}(1 ; p, 0)$. It is easy to prove that this cannot be optimal.

We can calculate the value of being in state $s=\left(B, a, z_{-1}, \zeta\right)=(B, 1,1, \zeta)$ as

$$
V(B, 1,1, \zeta ; p, 0)=\frac{u((1-\theta) \bar{y}, \theta \bar{y}-(1-\beta) B)}{1-\beta}
$$

The calculation of utility when default has occurred, when $z=0$, is mechanical. In this case $B=0$ and

$$
\begin{gathered}
c=(1-\theta) \overline{Z y} \\
g=\theta Z \bar{y} .
\end{gathered}
$$


Notice that, once a default has occurred, $\zeta$ and $\pi$ are irrelevant. Consequently, when $s=\left(B, a, z_{-1}, \zeta\right)=(B, 1,0, \zeta)$

$$
V(B, 1,0, \zeta ; p, 0)=\frac{u((1-\theta) Z \bar{y}, \theta Z \bar{Z})}{1-\beta},
$$

Let us calculate $\bar{b}(1 ; p, 0)$. Let $V_{n}(B, a, q ; p, \pi)$ be the value of not defaulting. The utility of repaying $B$ even if the international bankers do not lend is

$$
V_{n}(B, 1,0 ; p, 0)=u((1-\theta) \bar{y}, \theta \bar{y}-B)+\frac{\beta u((1-\theta) \bar{y}, \theta \bar{y})}{1-\beta},
$$

while the utility of defaulting $V_{d}(B, a, q ; p, \pi)$ is

$$
V_{d}(B, 1,0 ; p, 0)=\frac{u((1-\theta) Z \bar{y}, \theta Z \bar{y})}{1-\beta} .
$$

Consequently, $\bar{b}(1 ; p, 0)$ is determined by the equation

$$
\begin{gathered}
V_{n}(\bar{b}(1 ; p, 0), 1,0 ; p, 0)=V_{d}(\bar{b}(1 ; p, 0), 1,0 ; p, 0) \\
u((1-\theta) \bar{y}, \theta \bar{y}-\bar{b}(1 ; p, 0))+\frac{\beta u((1-\theta) \bar{y}, \theta \bar{y})}{1-\beta}=\frac{u((1-\theta) Z \bar{y}, \theta Z \bar{y})}{1-\beta} \\
u((1-\theta) Z \bar{y}, \theta Z \bar{y})-u((1-\theta) \bar{y}, \theta \bar{y}-\bar{b}(1 ; p, 0))=\frac{\beta}{1-\beta}(u((1-\theta) \bar{y}, \theta \bar{y})-u((1-\theta) Z \bar{y}, \theta Z \bar{y})) .
\end{gathered}
$$

Let us now characterize $\bar{B}(1 ; p, 0)$. We first find the stationary upper limit on debt $\bar{B}^{s}(1 ; p, 0)$ and then show that $\bar{B}(1 ; p, 0)=\bar{B}^{s}(1 ; p, 0)$. Suppose that international lenders set $q=\beta$ when $a=1$. Then, if the government decides to repay its debt

$$
V_{n}(B, 1, \beta ; p, 0)=\frac{u((1-\theta) \bar{y}, \theta \bar{y}-(1-\beta) B)}{1-\beta},
$$

while the value of defaulting is

$$
V_{d}(B, 1, \beta ; p, 0)=u(\theta Z \bar{y},(1-\theta) Z \bar{y}+\beta B)+\frac{\beta u(\theta Z \bar{y},(1-\theta) Z \bar{y})}{1-\beta} .
$$

Consequently, $\bar{B}^{s}(1 ; p, 0)$ is determined by the equation 


$$
\begin{gathered}
V_{n}\left(\bar{B}^{s}(1 ; p, 0), 1, \beta ; p, 0\right)=V_{d}\left(\bar{B}^{s}(1 ; p, 0), 1, \beta ; p, 0\right) \\
\frac{u\left((1-\theta) \bar{y}, \theta \bar{y}-(1-\beta) \bar{B}^{s}(1 ; p, 0)\right)}{1-\beta}=u\left((1-\theta) Z \bar{y}, \theta Z \bar{y}+\beta \bar{B}^{s}(1 ; p, 0)\right)+\frac{\beta u((1-\theta) Z \bar{y}, \theta Z \bar{y})}{1-\beta} \\
u\left((1-\theta) Z \bar{y}, \theta Z \bar{y}+\beta \bar{B}^{s}(1 ; p, 0)\right)-u\left((1-\theta) \bar{y}, \theta \bar{y}-(1-\beta) \bar{B}^{s}(1 ; p, 0)\right) \\
\cdot=\frac{\beta}{1-\beta}\left(u\left((1-\theta) \bar{y}, \theta \bar{y}-(1-\beta) \bar{B}^{s}(1 ; p, 0)\right)-u((1-\theta) Z \bar{y}, \theta Z \bar{y})\right)
\end{gathered}
$$

Suppose that, at $t=0$, the government finds itself with $B_{0}>\bar{B}^{s}(1 ; p, 0)$. Then it cannot be optimal to run down its debt to $B_{1} \leq \bar{B}^{s}(1 ; p, 0)$ in one period, setting

$$
g_{0}=\theta \bar{y}-B_{0}+\beta B_{1}
$$

in $t=0$ and

$$
g_{t}=\theta \bar{y}-(1-\beta) B_{1}
$$

thereafter. To demonstrate this, suppose, to the contrary, that

$$
\begin{aligned}
& u\left((1-\theta) \bar{y}, \theta \bar{y}-B_{0}+\beta B_{1}\right)+\frac{\beta u\left((1-\theta) \bar{y}, \theta \bar{y}-(1-\beta) B_{1}\right)}{1-\beta} \\
& \quad \geq u\left((1-\theta) Z \bar{y}, \theta Z \bar{y}+\beta B_{0}\right)+\frac{\beta u((1-\theta) Z \bar{y}, \theta Z \bar{y})}{1-\beta}
\end{aligned} .
$$

If we choose $B_{1}$ to maximize the left hand side of this inequality, the utility of not defaulting, we set $B_{1}=B_{0}$. This implies that

$$
\begin{aligned}
& u\left((1-\theta) \bar{y}, \theta \bar{y}-B_{0}+\beta B_{0}\right)+\frac{\beta u\left((1-\theta) \bar{y}, \theta \bar{y}-(1-\beta) B_{0}\right)}{1-\beta} \\
& \quad \geq u\left((1-\theta) \bar{y}, \theta \bar{y}-B_{0}+\beta B_{1}\right)+\frac{\beta u\left((1-\theta) \bar{y}, \theta \bar{y}-(1-\beta) B_{1}\right)}{1-\beta}
\end{aligned}
$$

for any $B_{1} \neq B_{0}$. This, however, contradicts or assumption that $B_{0}>\bar{B}^{s}(1 ; p, 0)$.

Let us now consider the case where $\pi>0$. First, observe that

$$
\bar{b}(1 ; p, \pi)=\bar{b}(1 ; p, 0)
$$


Suppose that $B_{0}>\bar{b}(1 ; p, \pi)$ and the government decides to reduce $B$ to $\bar{b}(1 ; p, \pi)$ in $T$ periods, $T=1,2, \ldots, \infty$. The first order conditions for the government's problem imply that

$$
g_{t}=g^{T}\left(B_{0} ; \pi\right) .
$$

The government's budget constraints are

$$
\begin{gathered}
g^{T}\left(B_{0} ; \pi\right)+B_{0}=\theta \bar{y}+\beta(1-\pi) B_{1} \\
g^{T}\left(B_{0} ; \pi\right)+B_{1}=\theta \bar{y}+\beta(1-\pi) B_{2} \\
\vdots \\
g^{T}\left(B_{0} ; \pi\right)+B_{T-2}=\theta \bar{y}+\beta(1-\pi) B_{T-1} \\
g^{T}\left(B_{0} ; \pi\right)+B_{T-1}=\theta \bar{y}+\beta \bar{b}(1 ; p, \pi) .
\end{gathered}
$$

Multiply each equation by $(\beta(1-\pi))^{t}$ and adding, we obtain

$$
\begin{gathered}
\sum_{t=0}^{T-1}(\beta(1-\pi))^{t} g^{T}\left(B_{0} ; \pi\right)+B_{0}=\sum_{t=0}^{T-1}(\beta(1-\pi))^{t} \theta \bar{y}+(\beta(1-\pi))^{T-1} \beta \bar{b}(1 ; p, \pi) \\
g^{T}\left(B_{0} ; \pi\right)=\theta \bar{y}-\frac{1-\beta(1-\pi)}{1-(\beta(1-\pi))^{T}}\left(B_{0}-(\beta(1-\pi))^{T-1} \beta \bar{b}(1 ; p, \pi)\right) .
\end{gathered}
$$

Notice that

$$
g^{\infty}\left(B_{0} ; \pi\right)=\lim _{T \rightarrow \infty} g^{T}\left(B_{0} ; \pi\right)=\theta \bar{y}-(1-\beta(1-\pi)) B_{0} .
$$

We can compute the value $V^{T}\left(B_{0} ; \pi\right)$ of each of the policies of running down the debt in $T$ periods, $T=1,2, \ldots, \infty$. Letting $V_{t}^{T}\left(B_{0} ; \pi\right)$ be the value of the policy where there are still $t$ periods to go in running debt, we can write

$$
\begin{gathered}
V_{T}^{T}\left(B_{0} ; \pi\right)=u\left((1-\theta) \bar{y}, g^{T}\left(B_{0} ; \pi\right)\right)+\beta(1-\pi) V_{T-1}^{T}\left(B_{0} ; \pi\right)+\frac{\beta \pi u((1-\theta) Z \bar{y}, \theta Z \bar{y})}{1-\beta} \\
V_{T-1}^{T}\left(B_{0} ; \pi\right)=u\left((1-\theta) \bar{y}, g^{T}\left(B_{0} ; \pi\right)\right)+\beta(1-\pi) V_{T-2}^{T}\left(B_{0} ; \pi\right)+\frac{\beta \pi u((1-\theta) Z \bar{y}, \theta Z \bar{y})}{1-\beta} \\
\vdots \\
V_{2}^{T}\left(B_{0} ; \pi\right)=u\left((1-\theta) \bar{y}, g^{T}\left(B_{0} ; \pi\right)\right)+\beta(1-\pi) V_{1}^{T}\left(B_{0} ; \pi\right)+\frac{\beta \pi u((1-\theta) Z \bar{y}, \theta Z \bar{y})}{1-\beta}
\end{gathered}
$$




$$
V_{1}^{T}\left(B_{0} ; \pi\right)=u\left((1-\theta) \bar{y}, g^{T}\left(B_{0} ; \pi\right)\right)+\frac{\beta u((1-\theta) \bar{y}, \theta \bar{y})}{1-\beta}
$$

Notice that $g$ increases from $g^{T}\left(B_{0} ; \pi\right)$ to $\theta \bar{y}$ in period $T$. To calculate $V^{T}\left(B_{0} ; \pi\right)$, we use backwards induction

$$
\begin{gathered}
V_{2}^{T}\left(B_{0} ; \pi\right)=(1+\beta(1-\pi)) u\left((1-\theta) \bar{y}, g^{T}\left(B_{0} ; \pi\right)\right) \\
+\frac{\beta \pi u((1-\theta) Z \bar{y}, \theta Z \bar{y})}{1-\beta} \\
+\beta(1-\pi) \frac{\beta u((1-\theta) \bar{y}, \theta \bar{y})}{1-\beta} \\
V_{3}^{T}\left(B_{0} ; \pi\right)=\left(1+\beta(1-\pi)+(\beta(1-\pi))^{2}\right) u\left((1-\theta) \bar{y}, g^{T}\left(B_{0} ; \pi\right)\right) \\
+(1+\beta(1-\pi)) \frac{\beta \pi u((1-\theta) Z \bar{y}, \theta Z \bar{y})}{1-\beta} \\
+(\beta(1-\pi))^{2} \frac{\beta u((1-\theta) \bar{y}, \theta \bar{y})}{1-\beta} \\
V_{T}^{T}\left(B_{0} ; \pi\right)=\left(1+\beta(1-\pi)+(\beta(1-\pi))^{2}+\ldots+(\beta(1-\pi))^{T-1}\right) u\left((1-\theta) \bar{y}, g^{T}\left(B_{0} ; \pi\right)\right) \\
+\left(1+\beta(1-\pi)+(\beta(1-\pi))^{2}+\ldots+(\beta(1-\pi))^{T-2}\right) \frac{\beta \pi u((1-\theta) Z \bar{y}, \theta Z \bar{y})}{1-\beta} \\
+(\beta(1-\pi))^{T-2} \frac{\beta u((1-\theta) \bar{y}, \theta \bar{y})}{1-\beta}
\end{gathered}
$$

and, of course, $V^{T}\left(B_{0} ; \pi\right)=V_{T}^{T}\left(B_{0} ; \pi\right)$ :

$$
\begin{aligned}
& V^{T}\left(B_{0} ; \pi\right)=\frac{1-(\beta(1-\pi))^{T}}{1+\beta(1-\pi)} u\left((1-\theta) \bar{y}, g^{T}\left(B_{0} ; \pi\right)\right)+\frac{1-(\beta(1-\pi))^{T-1}}{1+\beta(1-\pi)} \frac{\beta \pi u((1-\theta) Z y, \theta Z \bar{y})}{1-\beta} \\
& \quad+(\beta(1-\pi))^{T-2} \frac{\beta u((1-\theta) \bar{y}, \theta \bar{y})}{1-\beta}
\end{aligned}
$$

Notice that

$$
V^{\infty}\left(B_{0} ; \pi\right)=\frac{u\left((1-\theta) \bar{y}, \theta \bar{y}-(1-\beta(1-\pi)) B_{0}\right)}{1+\beta(1-\pi)}+\frac{\beta \pi u((1-\theta) Z \bar{y}, \theta Z \bar{y})}{(1-\beta)(1+\beta(1-\pi))}
$$

To find $\bar{B}(1 ; p, \pi)$, we solve 


$$
\begin{aligned}
& \max \left[V^{1}(\bar{B}(1 ; p, \pi)), V^{2}(\bar{B}(1 ; p, \pi)), \ldots, V^{\infty}(\bar{B}(1 ; p, \pi) ; \pi)\right] \\
& \quad=u((1-\theta) Z \bar{y}, \theta Z \bar{y}+\beta(1-\pi) \bar{B}(1 ; p, \pi)))+\frac{\beta u((1-\theta) Z \bar{y}, \theta Z \bar{y})}{1-\beta} .
\end{aligned}
$$

Our arguments have produced the following analytical characterization of $V(B, 1,1, \zeta ; p, \pi)$ :

$$
V(B, 1,1, \zeta ; p, \pi)= \begin{cases}\frac{u((1-\theta) \bar{y}, \theta \bar{y})}{1-\beta} & \text { if } B \leq \bar{b}(1 ; p, \pi) \\ \frac{\max \left[V^{1}(B ; \pi), V^{2}(B ; \pi), \ldots, V^{\infty}(B ; \pi)\right]}{\frac{u((1-\theta) Z \bar{y}, \theta Z \bar{y})}{1-\beta}} & \text { if } \bar{b}(1 ; p, \pi)<B \leq \bar{B}(1 ; p, \pi), \zeta \leq 1-\pi \\ \frac{u((1-\theta) Z \bar{y}, \theta Z \bar{y})}{1-\beta} & \text { if } \bar{b}(1 ; p, \pi)<B \leq \bar{B}(1 ; p, \pi), 1-\pi<\zeta \\ & \text { if } \bar{B}(1 ; p, \pi)<B\end{cases}
$$

Some of the different possibilities for optimal government strategies — which vary with the initial debt — are illustrated in figure 5.

Figure 5: Optimal debt policy with self-fulfilling crises

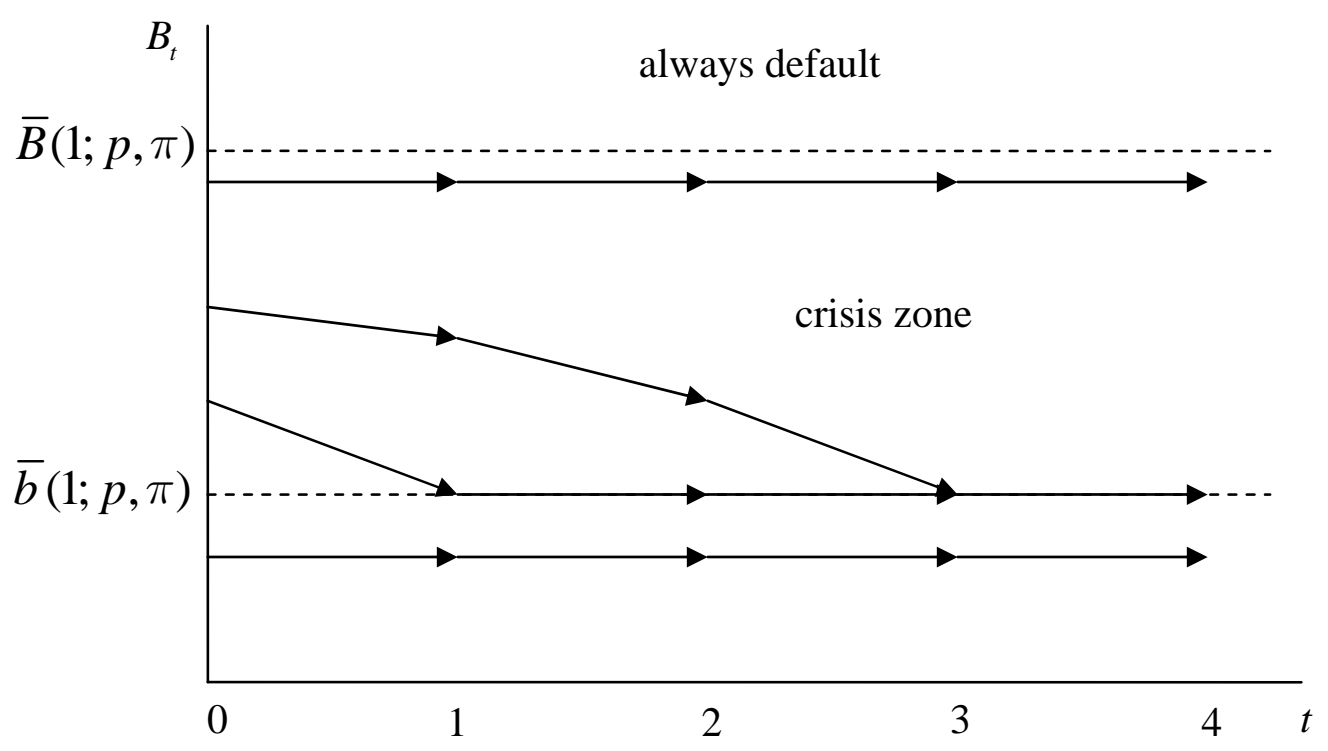




\section{Gambling for redemption without self-fulfilling crises}

Suppose now that $a=0$ and $\pi=0$. That is, no self-fulfilling crises are possible, but the private sector is in a recession and faces the probability $p, 1>p>0$, of recovering in every period. We can also interpret this as the limiting case in which crises can occur, but the government and the international bankers assign probability $\pi=0$ to them.

Figure 7: Uncertainty tree with recession path highlighted

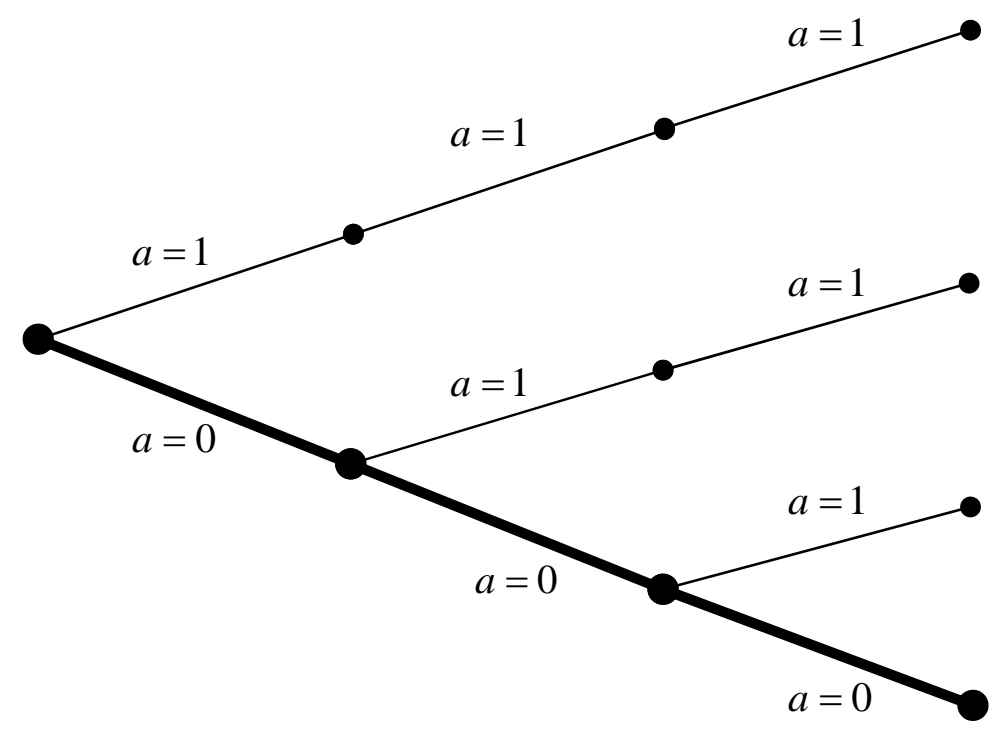

In this section, we argue that the optimal government policies is to increase its debt as long as $a=0$. In fact, if the country is unlucky in the sense that $a=0$ long enough, the government may choose to eventually default. Consequently, the upper limits on the debt, $\bar{B}(0 ; p, 0)$ and $\bar{B}(1 ; p, 0)$ are crucial for our analysis. Notice that, since

$$
\bar{B}(1 ; p, 0)=\bar{B}(1 ; 0,0),
$$

because the probability of recovery does not matter once it has occurred, we have already derived a condition that determines $\bar{B}(1 ; p, 0)$. 


$$
\begin{aligned}
& u((1-\theta) Z \bar{y}, \theta Z \bar{y}+\beta \bar{B}(1 ; p, 0))-u((1-\theta) \bar{y}, \theta \bar{y}-(1-\beta) \bar{B}(1 ; p, 0)) \\
& \quad=\frac{\beta}{1-\beta}(u((1-\theta) \bar{y}, \theta \bar{y}-(1-\beta) \bar{B}(1 ; p, 0))-u((1-\theta) Z \bar{y}, \theta \overline{Z y}))
\end{aligned} .
$$

To determine $\bar{B}(0 ; p, 0)$, we suppose that the government runs up its debt to some level $B \leq \bar{B}(0 ; p, 0)$, borrows $\bar{B}(0 ; p, 0)<B^{\prime} \leq \bar{B}(1 ; p, 0)$ at price $\beta p$, then repays the next period if the private sector recovers and on defaults otherwise. The value of borrowing $\bar{B}(1 ; p, 0)$ at price $\beta p$, repaying the current debt, and then repaying in the next period if the private sector recovers and on defaulting otherwise is

$$
\begin{aligned}
& V_{n}(B, 0,1 ; p, 0)=u((1-\theta) A \bar{y}, \theta A \bar{y}+\beta p \bar{B}(1 ; p, 0)-B) \\
& \quad+\beta(1-p)\left(\frac{u((1-\theta) A Z \bar{y}, \theta A Z \bar{y})}{1-\beta(1-p)}+\frac{\beta p u((1-\theta) Z \bar{y}, \theta Z \bar{y})}{(1-\beta)(1-\beta(1-p))}\right) \\
& \quad+\frac{\beta p}{1-\beta} u((1-\theta) \bar{y}, \theta \bar{y}-(1-\beta) \bar{B}(1 ; p, 0))
\end{aligned}
$$

The value of borrowing $\bar{B}(1 ; p, 0)$ at price $\beta p$ and then defaulting is

$$
\begin{aligned}
& V_{d}(B, 0,1 ; p, 0)=u((1-\theta) A Z \bar{y}, \theta A Z \bar{y}+\beta p \bar{B}(1 ; p, 0)) \\
& \quad+\beta(1-p)\left(\frac{u((1-\theta) A Z \bar{y}, \theta A Z \bar{y})}{1-\beta(1-p)}+\frac{\beta p u((1-\theta) Z \bar{y}, \theta Z \bar{y})}{(1-\beta)(1-\beta(1-p))}\right) \\
& \quad+\frac{\beta p}{1-\beta} u((1-\theta) Z \bar{y}, \theta Z \bar{y})
\end{aligned}
$$

The equation that determines $\bar{B}(0 ; p, 0)$ is, therefore,

$$
\begin{gathered}
V_{n}(\bar{B}(0 ; p, 0), 0,1 ; p, 0)=V_{d}(\bar{B}(0 ; p, 0), 0,1 ; p, 0) \\
u((1-\theta) A \bar{y}, \theta A \bar{y}+\beta p \bar{B}(1 ; p, 0)-\bar{B}(0 ; p, 0))+\frac{\beta p}{1-\beta} u((1-\theta) \bar{y}, \theta \bar{y}-(1-\beta) \bar{B}(1 ; p, 0)) \\
=u((1-\theta) A Z \bar{y}, \theta A Z \bar{y}+\beta p \bar{B}(1 ; p, 0))+\frac{\beta p}{1-\beta} u((1-\theta) Z \bar{y}, \theta Z \bar{y})
\end{gathered}
$$

The government may, in fact, choose a lower level of the debt than $\bar{B}(1 ; p, 0)$, but $\bar{B}(0 ; p, 0)$ is the highest level of the debt $B^{\prime}$ at which the government can borrow at price 
$q\left(B^{\prime}, s ; p, \pi\right)=\beta$. Indeed, if the constraint $B^{\prime} \leq \bar{B}(1 ; p, 0)$ does not bind, we can calculate the optimal $B^{\prime}$ by solving

$$
\begin{aligned}
& \max u\left((1-\theta) A \bar{y}, \theta A \bar{y}+\beta p B^{\prime}-B\right) \\
& \quad+\beta(1-p)\left(\frac{u((1-\theta) A Z \bar{y}, \theta A Z \bar{y})}{1-\beta(1-p)}+\frac{\beta p u((1-\theta) Z \bar{y}, \theta Z \bar{y})}{(1-\beta)(1-\beta(1-p))}\right) \\
& \quad+\frac{\beta p}{1-\beta} u\left((1-\theta) \bar{y}, \theta \bar{y}-(1-\beta) B^{\prime}\right)
\end{aligned}
$$

The first order condition is

$$
u_{g}\left((1-\theta) A \bar{y}, \theta A \bar{y}+\beta p B^{\prime}-B\right)=u_{g}\left((1-\theta) \bar{y}, \theta \bar{y}-(1-\beta) B^{\prime}\right)
$$

Letting $\hat{B}^{\prime}(B)$ be the solution to this problem,

$$
B^{\prime}(B)=\min \left[\hat{B}^{\prime}(B), \bar{B}(1 ; p, 0)\right]
$$

There are two cases:

1. The government chooses to never violate the constraint $B \leq \bar{B}(0 ; p, 0)$, and the optimal debt converges to $\bar{B}(0 ; p, 0)$ if $a=0$ for sufficiently long.

2. The government chooses to default in $T$ periods if $a=0$ sufficiently long.

The crucial parameter in determining which of these two cases the economy is in is the default penalty factor $Z$. If $Z$ is sufficiently low, the government will choose to never default. If $Z$ is close to 1, it will optimally choose to default after a sufficiently long number of periods in which $a=0$.

\subsection{Equilibrium with no default}

Let us first consider the case where government chooses to never violate the constraint $B \leq \bar{B}(0 ; p, 0)$. For this to be an equilibrium, two things must be true:

1. The expected discounted value of steady state utility at $B=\bar{B}(0 ; p, 0)$ must be higher than that of defaulting after bankers have purchased $B^{\prime}=\bar{B}(0 ; p, 0)$ at price $\beta$, 


$$
\begin{aligned}
& u((1-\theta) A \bar{y}, \theta A \bar{y}-(1-\beta) \bar{B}(0 ; p, 0)) \\
& \quad+\beta(1-p)\left(\frac{u((1-\theta) A \bar{y}, \theta A \bar{y}-(1-\beta) \bar{B}(0 ; p, 0))}{1-\beta(1-p)}+\frac{\beta p u((1-\theta) \bar{y}, \theta \bar{y}-(1-\beta) \bar{B}(0 ; p, 0))}{(1-\beta)(1-\beta(1-p))}\right) \\
& \quad+\frac{\beta p}{1-\beta} u((1-\theta) \bar{y}, \theta \bar{y}-(1-\beta) \bar{B}(0 ; p, 0)) \\
& \quad \geq u((1-\theta) A Z \bar{y}, \theta A Z \bar{y}+\beta \bar{B}(0 ; p, 0)) \\
& \quad+\beta(1-p)\left(\frac{u((1-\theta) A Z \bar{y}, \theta A Z \bar{y})}{1-\beta(1-p)}+\frac{\beta p u((1-\theta) Z \bar{y}, \theta Z \bar{y})}{(1-\beta)(1-\beta(1-p))}\right) \\
& \quad+\frac{\beta p}{1-\beta} u((1-\theta) Z \bar{y}, \theta Z \bar{y})
\end{aligned} .
$$

2. The expected discounted value of steady state utility at $B=\bar{B}(0 ; p, 0)$ must be higher than that of running up the debt one more time at price $\beta p$, repaying if the private sector recovers, and defaulting otherwise,

$$
\begin{aligned}
& u((1-\theta) A \bar{y}, \theta A \bar{y}-(1-\beta) \bar{B}(0 ; p, 0)) \\
& \quad+\beta(1-p)\left(\frac{u((1-\theta) A \bar{y}, \theta A \bar{y}-(1-\beta) \bar{B}(0 ; p, 0))}{1-\beta(1-p)}+\frac{\beta p u((1-\theta) \bar{y}, \theta \bar{y}-(1-\beta) \bar{B}(0 ; p, 0))}{(1-\beta)(1-\beta(1-p))}\right) \\
& \quad+\frac{\beta p}{1-\beta} u((1-\theta) \bar{y}, \theta \bar{y}-(1-\beta) \bar{B}(0 ; p, 0)) \\
& \quad \geq u\left((1-\theta) A \bar{y}, \theta A \bar{y}+\beta p B^{\prime}(\bar{B}(0 ; p, 0))-\bar{B}(0 ; p, 0)\right) \\
& \quad+\beta(1-p)\left(\frac{u((1-\theta) A Z \bar{y}, \theta A Z \bar{y})}{1-\beta(1-p)}+\frac{\beta p u((1-\theta) Z \bar{y}, \theta Z \bar{y})}{(1-\beta)(1-\beta(1-p))}\right) \\
& \quad+\frac{\beta p}{1-\beta} u\left((1-\theta) \bar{y}, \theta \bar{y}-(1-\beta) B^{\prime}(\bar{B}(0 ; p, 0))\right)
\end{aligned}
$$

where $B^{\prime}(B)=\min \left[\hat{B}^{\prime}(B), \bar{B}(1 ; p, 0)\right]$.

If these two conditions are satisfied, the optimal government policy is the solution to the dynamic programming problem

$$
\begin{gathered}
V(B, a)=\max u\left((1-\theta) A^{1-a} \bar{y}, \theta A^{1-a} \bar{y}+\beta B^{\prime}-B\right)+\beta E V\left(B^{\prime}, a^{\prime}\right) \\
\text { s.t. } B \leq \bar{B}(0 ; p, 0)
\end{gathered}
$$

We write Bellman's equation explicitly as 


$$
\begin{gathered}
\left.V(B, 0)=\max u\left((1-\theta) A \bar{y}, \theta A \bar{y}+\beta B^{\prime}-B\right)+\beta(1-p) V\left(B^{\prime}, 0\right)+\beta p\right) V\left(B^{\prime}, 1\right) \\
V(B, 1)=\max u\left((1-\theta) \bar{y}, \theta \bar{y}+\beta B^{\prime}-B\right)+\beta V\left(B^{\prime}, 1\right)
\end{gathered}
$$

The first order condition is

$$
\beta u_{g}\left((1-\theta) A^{1-a} \bar{y}, \theta A^{1-a} \bar{y}+\beta B^{\prime}-B\right)=\beta E V_{B}\left(B^{\prime}, a^{\prime}\right),
$$

while the envelope condition is

$$
V_{B}(B, a)=-u_{g}\left((1-\theta) A^{1-a} \bar{y}, \theta A^{1-a} \bar{y}+\beta B^{\prime}-B\right)
$$

The envelope condition implies $V(B, a)$ is decreasing in $B$. A standard argument - that the operator on the space of functions defined by Bellman's equations maps concave value functions into concave value functions - implies that $V(B, a)$ is concave in $B$.

Now, using the first order condition, we can use standard arguments to show that the policy function for debt $B^{\prime}(B, a)$ is increasing in $B$ while the policy function for government spending $g(B, a)$ is decreasing. Using our assumption that

$$
u_{g}((1-\theta) A \bar{y}, \theta A \bar{y}-b)>u_{g}((1-\theta) \bar{y}, \theta \bar{y}-b)
$$

we can argue that $B^{\prime}(0)>0$ and that it is impossible for $B^{\prime}(B)=B$ unless the constraint $B \leq \bar{B}(0 ; p, 0)$ binds, which implies that $B^{\prime}(B, 0)>B$. We have already argued that $B^{\prime}(B, 1)=B$. Figure 7 illustrates some optimal government strategies as functions of the initial debt. 
Figure 7: Optimal debt policy gambling for redemption when $B \leq \bar{B}(0 ; p, 0)$ binds

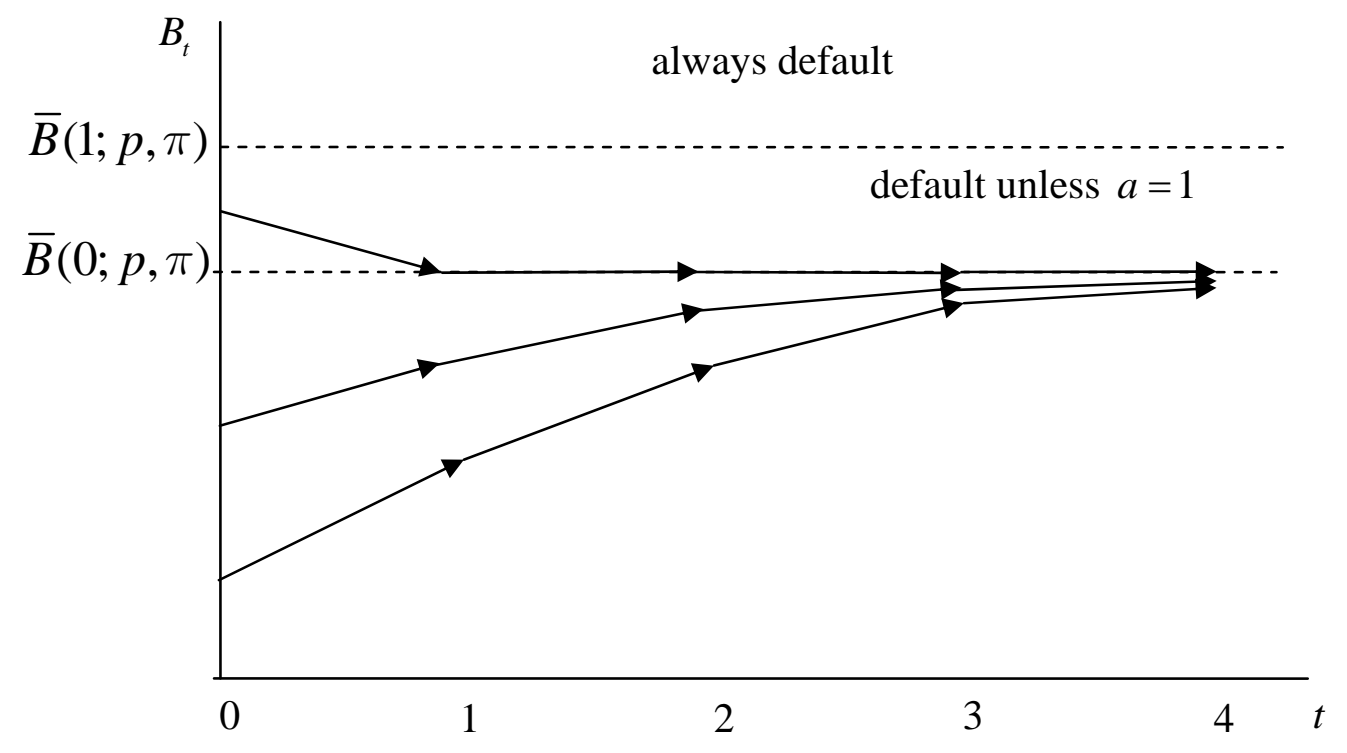

\subsection{Equilibrium with eventual default}

Let us now consider the case where government chooses to violate the constraint $B \leq \bar{B}(0 ; p, 0)$ with its sale of debt in period $T$, defaulting in period $T+1$ unless the private sector recovers. The optimal government policy along the branch of the uncertainty tree in which $a_{t}=0$ is the solution to the finite horizon dynamic programming problem

$$
\begin{gathered}
V_{t}\left(B_{t}, 0\right)=\max u\left((1-\theta) A \bar{y}, \theta A \bar{y}+\beta B_{t+1}-B_{t}\right)+\beta(1-p) V_{t+1}\left(B_{t+1}, 0\right)+\beta p \frac{\left.u\left((1-\theta) \bar{y}, \theta \bar{y}+(1-\beta) B_{t+1}\right)\right)}{1-\beta} \\
\text { s.t. } \bar{B}(1 ; p, 0) \geq B_{T+1} \geq \bar{B}(0 ; p, 0) \\
B_{T} \leq \bar{B}(0 ; p, 0) .
\end{gathered}
$$

We solve this by backwards induction with the terminal value function

$$
\begin{aligned}
V_{T}\left(B_{T}, 0\right)= & \max u\left((1-\theta) A \bar{y}, \theta A \bar{y}+\beta p B_{T+1}-B_{T}\right) \\
& +\beta(1-p) \frac{u((1-\theta) Z \bar{y}, \theta Z \bar{y}))}{1-\beta}+\beta p \frac{\left.u\left((1-\theta) \bar{y}, \theta \bar{y}+(1-\beta) B_{T+1}\right)\right)}{1-\beta}
\end{aligned}
$$

s.t. $B_{T+1} \leq \bar{B}(1 ; p, 0)$ 
We then choose the value of $T$ for which $V_{0}\left(B_{0}, 0\right)$ is maximal. As long the constraint $B_{T+1} \geq \bar{B}(0 ; p, 0)$ binds, we can increase the value of $V_{0}\left(B_{0}, 0\right)$ by increasing $T$.

Figure 7: Optimal debt policy gambling for redemption when $B \leq \bar{B}(0 ; p, 0)$ does not bind

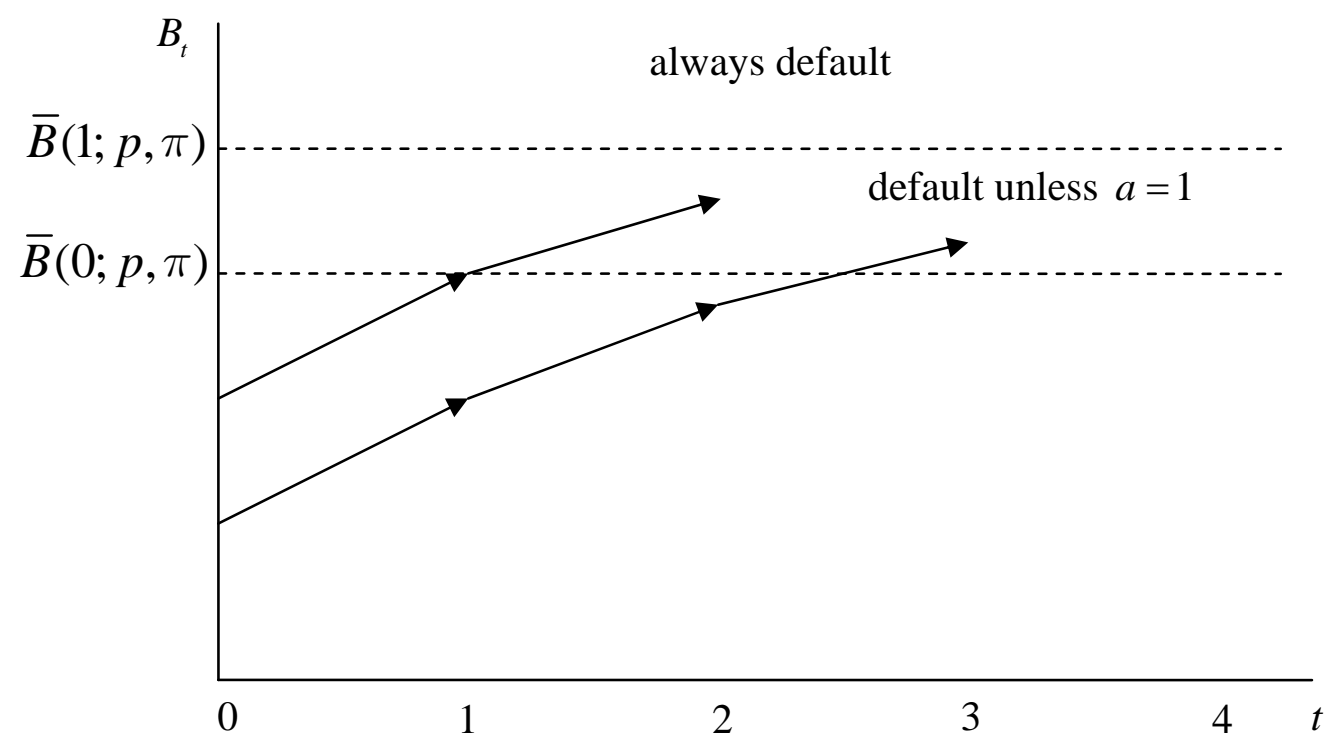

In figure 7, we illustrate two possibilities, which depend on $B_{0}$. In one $T=1$, and in the other $T=2$.

The algorithm for calculating the optimal policy on a grid of bond levels is a straightforward application of policy function iteration. Since we work backwards from the period in which the government borrows at price $\beta p$ and will default in the next period unless a recovery of the private sector occurs, let us reverse our labeling of the value functions and define

$$
\begin{aligned}
V_{0}(B, 0)= & \max u\left((1-\theta) A \bar{y}, \theta A \bar{y}+\beta p B^{\prime}-B\right) \\
& +\beta(1-p) \frac{u((1-\theta) Z \bar{y}, \theta Z \bar{y}))}{1-\beta}+\beta p \frac{\left.u\left((1-\theta) \bar{y}, \theta \bar{y}+(1-\beta) B^{\prime}\right)\right)}{1-\beta}
\end{aligned}
$$

s.t. $\bar{B}(0 ; p, 0) \leq B \leq \bar{B}(1 ; p, 0)$.

The steps of the algorithm are 
1. Solve for the value function $V_{0}(B, 0)$ and the policy function $B_{0}{ }^{\prime}(B)$ on a grid of bonds $B$ on the interval $[\underline{B}, \bar{B}(0 ; p, 0)]$. We can set the lower limit $\underline{B}$ equal to any value, including a negative value. In an application with a given initial stock of debt, we could set $\underline{B}=B_{0}$. We have already solved this problem analytically. The solution is $B^{\prime}(B)=\min \left[\hat{B}^{\prime}(B), \bar{B}(1 ; p, 0)\right]$ unless $B^{\prime}(B)<\bar{B}(0 ; p, 0)$, in which case $B_{0}{ }^{\prime}(B)=\bar{B}(0 ; p, 0)$. Consequently,

$$
B_{0}{ }^{\prime}(B)=\max \left[\bar{B}(0 ; p, 0), \min \left[\hat{B}^{\prime}(B), \bar{B}(1 ; p, 0)\right]\right] .
$$

It turns out that the values of $B$ for which $B^{\prime}(B)<\bar{B}(0 ; p, 0)$ are those for which it is not optimal to set $T=0$.

2. Let $t=0$, and set $\tilde{B}_{0}=\bar{B}(0 ; p, 0)$.

3. Solve for the value function $V_{t+1}(B, 0)$ and the policy function $B_{t+1}$ '(B) in Bellman's equation $V_{t+1}(B, 0)=\max u\left((1-\theta) A \bar{y}, \theta A \bar{y}+\beta B^{\prime}-B\right)+\beta(1-p) V_{t}\left(B^{\prime}, 0\right)+\beta p \frac{u((1-\theta) \bar{y}, \theta \bar{y}+(1-\beta) B))}{1-\beta}$. Let $\tilde{B}_{t}$ be the largest value of $B$ for which $V_{t+1}(B, 0) \geq V_{t}(B, 0)$.

4. Repeat step 3 until $\tilde{B}_{t}=\underline{B}$.

Let $T$ be such that $\tilde{B}_{T}=\underline{B}$. We can prove that $\underline{B}<\tilde{B}_{T-1}<\tilde{B}_{T-2}<\cdots<\tilde{B}_{1}<\bar{B}(0 ; p, 0)$. Our algorithm divides the interval $[\underline{B}, \bar{B}(0 ; p, 0)]$ into subintervals $\left[\underline{B}, \tilde{B}_{T-1}\right),\left[\tilde{B}_{T-1}, \tilde{B}_{T-2}\right), \ldots$, $\left[\tilde{B}_{1}, \bar{B}(0 ; p, 0)\right]$. If the initial capital stock $B_{0}$ is in the subinterval $\left[\tilde{B}_{t}, \tilde{B}_{t-1}\right]$, then the optimal government policy is to increase $B$, selling debt $B, \bar{B}(0 ; p, 0)<B \leq \bar{B}(1 ; p, 0)$, in period $t-1$, and defaulting in period $t$ unless the private sector recovers. The optimal sequence of debt is $B_{0}, B_{t-1}^{\prime}\left(B_{0}\right), B_{t-2}^{\prime}\left(B_{t-1}^{\prime}\left(B_{0}\right)\right) \ldots, B_{0}\left(B_{1}\left(\cdots\left(B_{t-1}{ }^{\prime}\left(B_{0}\right)\right)\right)\right)$.

\section{Results for the general model}

For the general model in which $a_{0}=0,1>p>0$, and $1>\pi>0$, figure 8 illustrates some of the distinctly different possible patterns of equilibrium dynamics. 
Figure 8: Four possible phase diagrams in general model

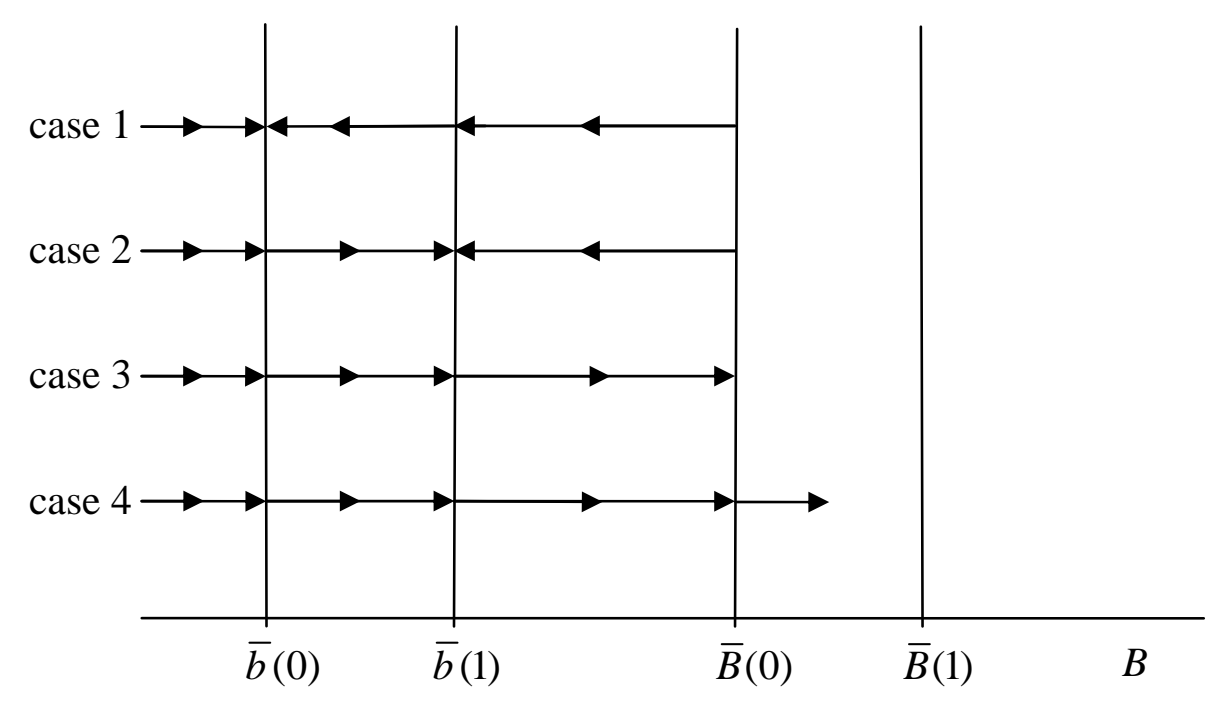

When debt is low enough, $B \leq b(0 ; p, \pi)$, the government necessarily runs up its debt, gambling for redemption. As debt becomes larger, however, the probability of a crisis increases and the price of bonds falls, as in figure 4. For high enough levels of debt, the benefits of running down debt to avoid a self-fulfilling crisis may dominate the benefits of gambling for redemption. For $\pi>0$ small enough, this never happens, and the government eventually defaults unless the private sector recovers to $a=1$. Otherwise, debt will stop at one of the fixed points $\bar{b}(0 ; p, \pi), \bar{b}(1 ; p, \pi)$, or $\bar{B}(0 ; p, \pi)$. There are, of course, also degenerate cases where optimal debt is constant in an interval.

We will present numerical experiments for each of the four different cases and illustrate how they depend on the parameters $A, Z, p$, and $\pi$. 


\subsection{Calibration of the model and quantitative results}

In order to solve for the equilibrium we need to choose a functional form for the utility function. We choose a $\log$ specification, i.e. $u(c, g)=\gamma \log (c)+(1-\gamma) \log (g)$. The parameters we choose for our benchmark scenario are the following:

Table 1: Parameter values in the Benchmark scenario

\begin{tabular}{|c|c|c|}
\hline Parameter & Value & Target \\
\hline $\mathrm{A}$ & 0.90 & Average gov’t revenue loss (see Figure 3) \\
\hline $\mathrm{Z}$ & 0.95 & As in Cole and Kehoe (1996) \\
\hline $\mathrm{p}$ & 0.20 & Average recovery in 5 years \\
\hline$\beta$ & 0.98 & Real interest rate of safe bonds $2 \%$ \\
\hline$\pi$ & 0.03 & Real interest rate in crisis zone 5\% \\
\hline$\gamma$ & 0.75 & Consumers value $c$ 3 times more than $g$ \\
\hline$\theta$ & 0.30 & Government revenues as a share of output \\
\hline
\end{tabular}

In Figure 9 we plot the policy functions, together with the debt thresholds (as described in Figure 8).

Figure 9: Policy functions in good (left panel) and bad (right) times
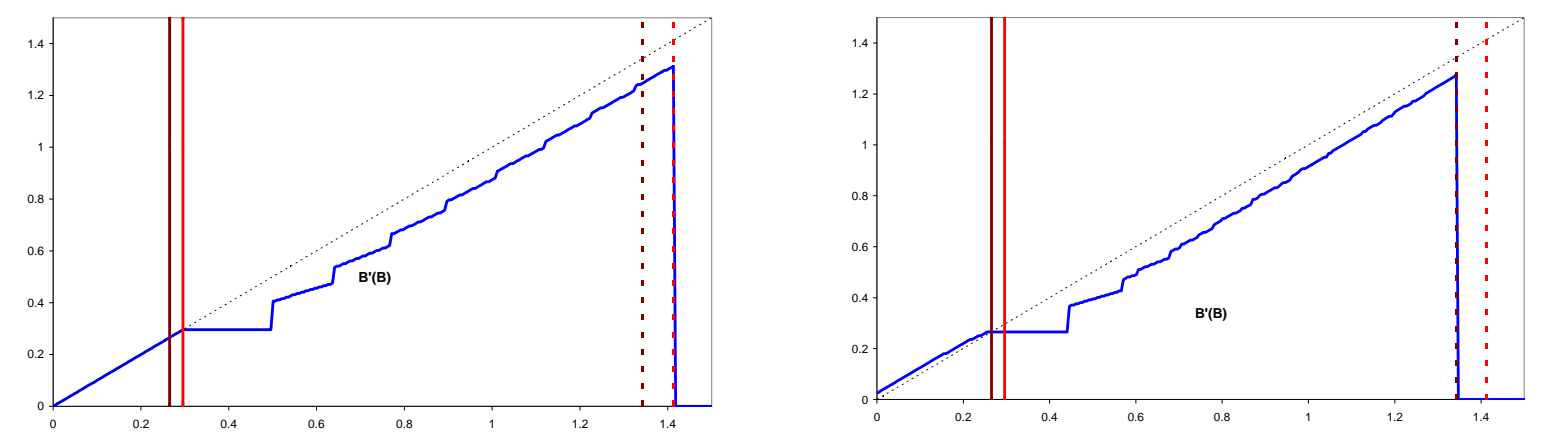

First, notice the value of the thresholds. The lower thresholds (in bad and good times, respectively) are for debt levels of 0.26 and 0.29 (relative to output in good times, which is 
normalized to 1). Any debt above these levels makes the economy vulnerable to a panic, in which case a crisis would occur and default would be optimal. Second, the upper thresholds (in bad and good times, respectively) are 1.38 and 1.41. Notice there are several countries that have levels of debt quite close to those. Greece was at the end of 2010 at 1.26, Italy was at 1.2, while Belgium or Ireland were around 1.

If the economy is in good times then the optimal policy is to keep debt constant when the economy is in the safe region and decrease debt step by step when the economy is in the crisis zone. This is exactly the policy prescription of Cole and Kehoe (2000). In bad times the optimal policy is to gamble for redemption up to the point where the economy enters the crisis zone. If the economy started in the crisis zone, then it would be optimal to decrease debt step by step to exit the crisis zone. Notice that in our benchmark scenario we would be in Case 1, as described in Figure 8.

Suppose now that the probability of a panic is very small, or alternatively that there exists an outside institution willing to bail out this economy by lending at the safe real interest rate (in our benchmark scenario $2 \%$ ). Then, the upper thresholds go up to around 2.25, however the policy function shifts up, so that there is gambling for redemption all the way until the upper limit. This situation is labeled as Case 3 in Figure 8.

Figure 10: Policy function in bad times for small $\pi$

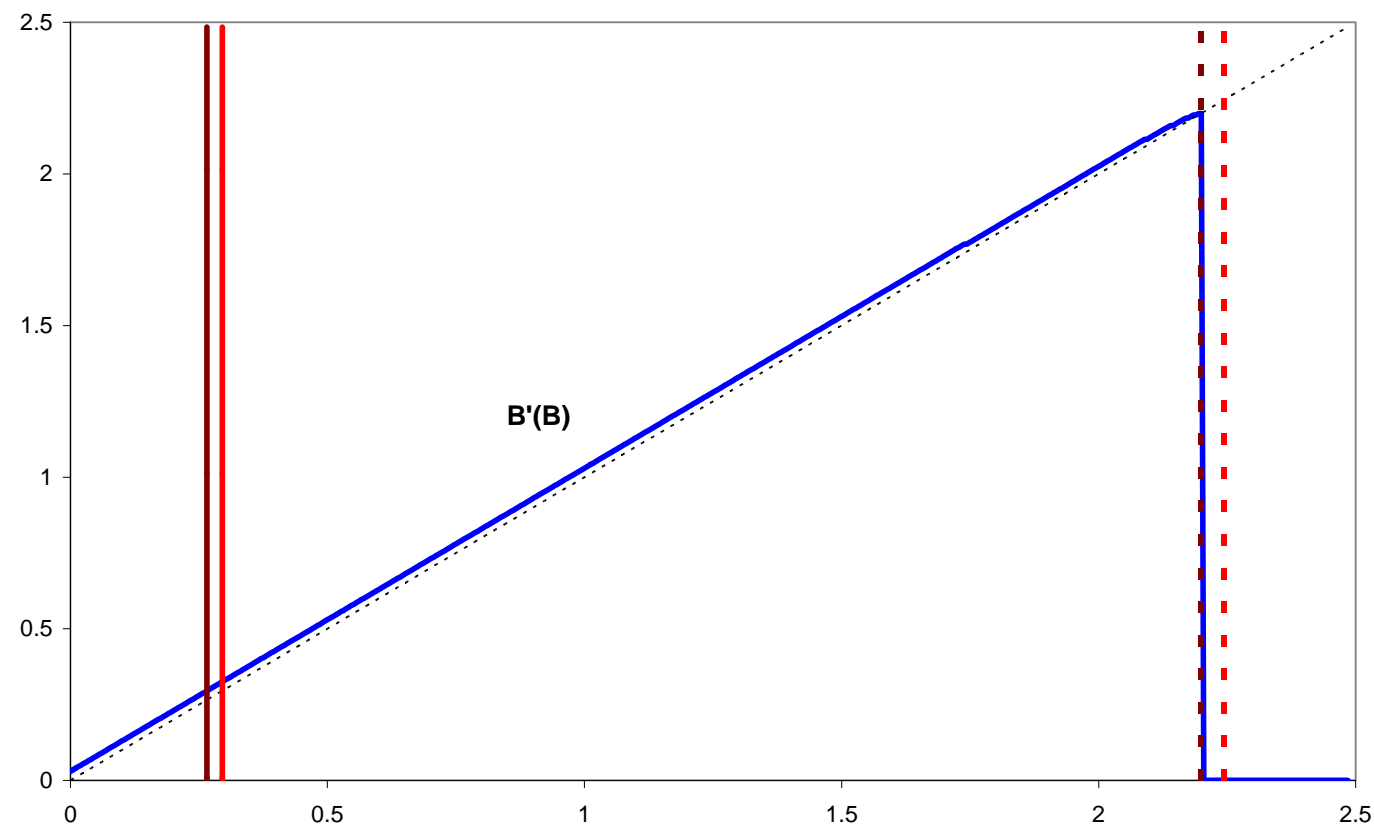


Notice that the existence of a potential bailout implies that it is optimal to gamble for redemption in situations where it wouldn't be optimal otherwise.

The specification of the economy as shown in Table 1 is done having in mind one period as one year, and in our model economy we only allow for one-period debt. Such a situation would mostly reflect developing economies that usually borrow very short term. The crisis zone is between $30 \%$ and $140 \%$ GDP, which would imply that substantial amounts of debt would have to be refinanced every period, and as a consequence panics might happen at relatively low debt to GDP ratios.

However, most European countries borrow at longer maturities. Including in the analysis debt of longer maturities would greatly complicate the analysis. There is a simple way to think of it, though. Imagine debt has a maturity of 6 years (which corresponds to the average maturity of debt for countries like Greece, Portugal or Spain) and is uniformly distributed over all the maturities. Then, every period 17\% (100/6) of the total debt must be refinanced. According to that interpretation, we simply choose to rescale the model so that a period is 6 years. We report the results in the following figure.

Figure 11: Policy functions in bad times with 6-year periods

\section{Normal}

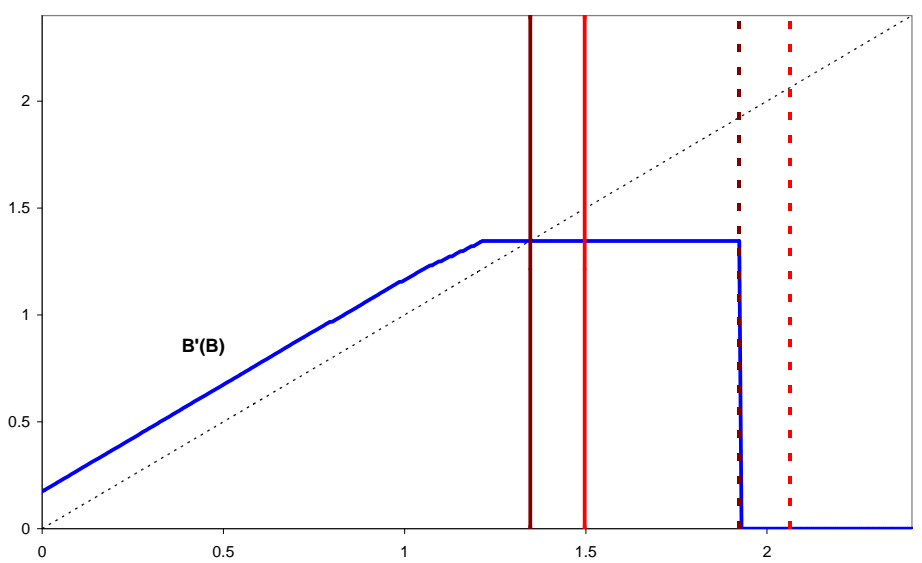

Low $\pi$

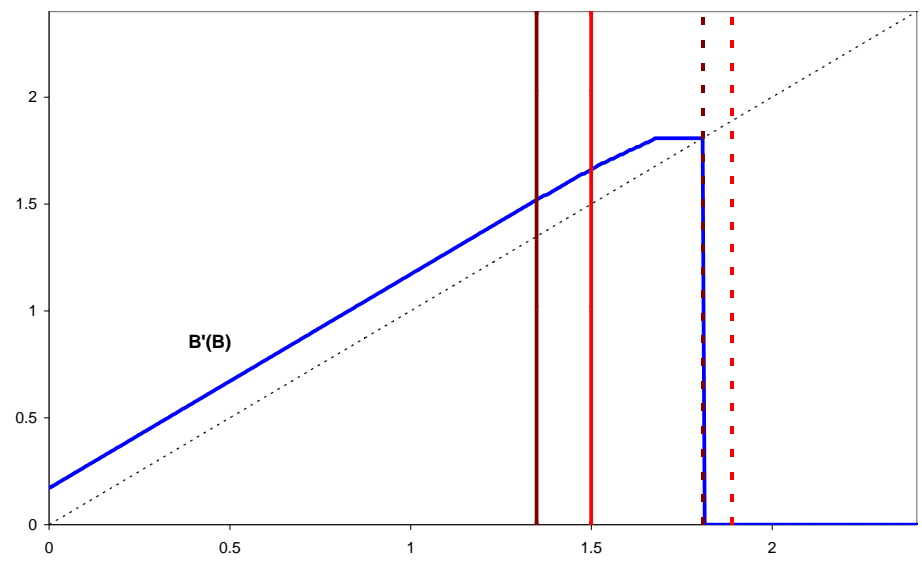

If the probability of a panic is equivalent to 3\% in annual terms (left panel), then the optimal strategy is to gamble for redemption in the safe zone until the economy reaches a steady state at the lower threshold that separates the safe zone from the crisis zone. If the economy starts in the crisis zone, then the optimal strategy would be to go back to the safe zone in one period. The safe zone ends at $130 \%$ debt to GDP (measured in yearly terms). 
Again here we observe that in response to a lower probability of a panic (or the access to financing at safe interest rates) the government finds optimal to gamble for redemption until the upper threshold of debt (which at the same time shifts to the left). This case is reported in the right panel. Thus, if there is a low probability of a panic (or some lender is willing to lend the government at the safe interest rate) then the optimal strategy is to gamble for redemption until debt reaches $180 \%$ of GDP in yearly terms.

\subsection{Sensitivity analysis}

In order to illustrate that many other scenarios are possible we will provide numerical results for various different scenarios in Figure 12.

Figure 12: Policy function if probability of a recovery is high

$$
\mathrm{A}=0.70
$$

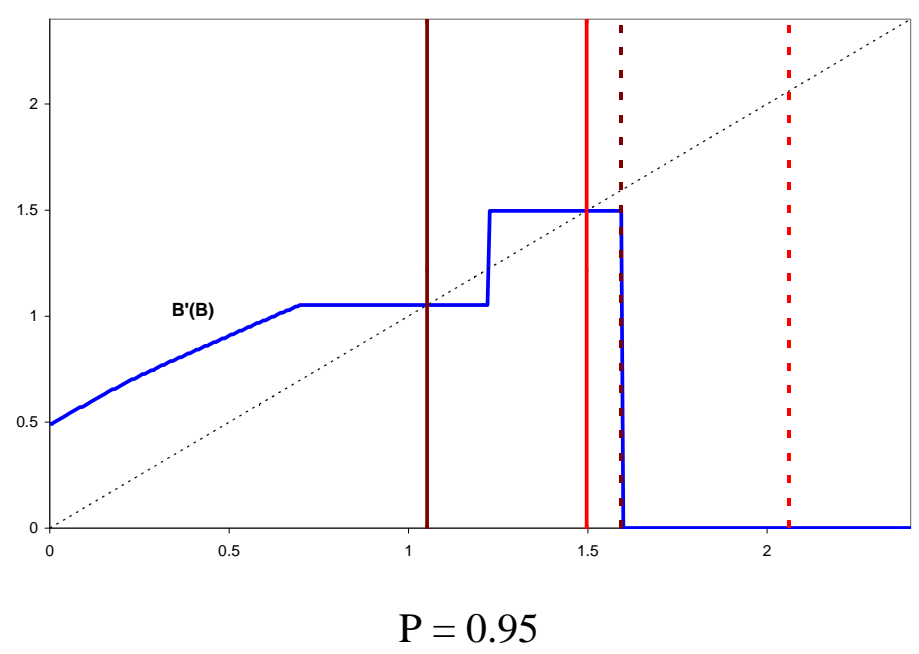

$\mathrm{Z}=0.5$

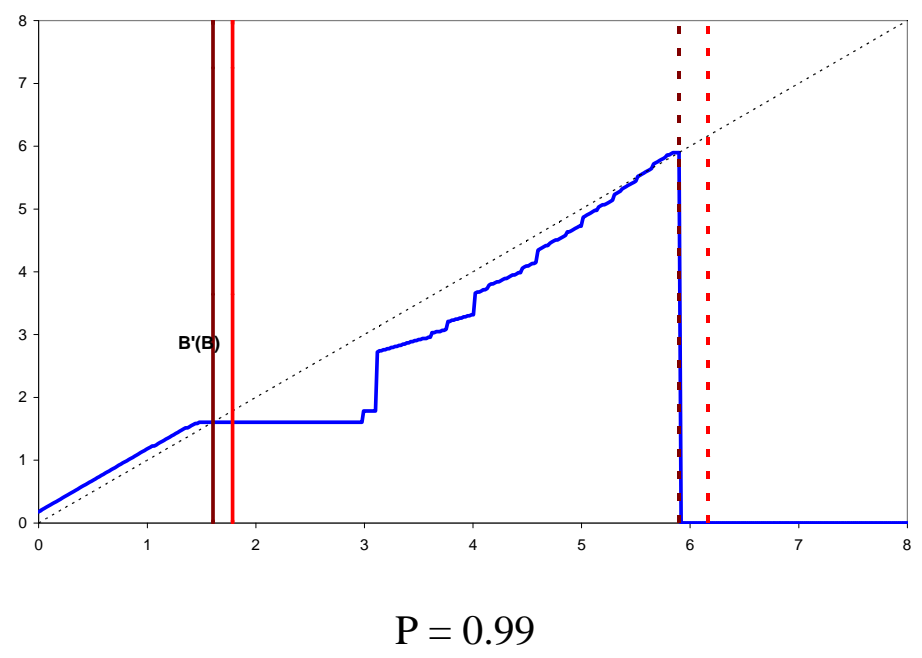



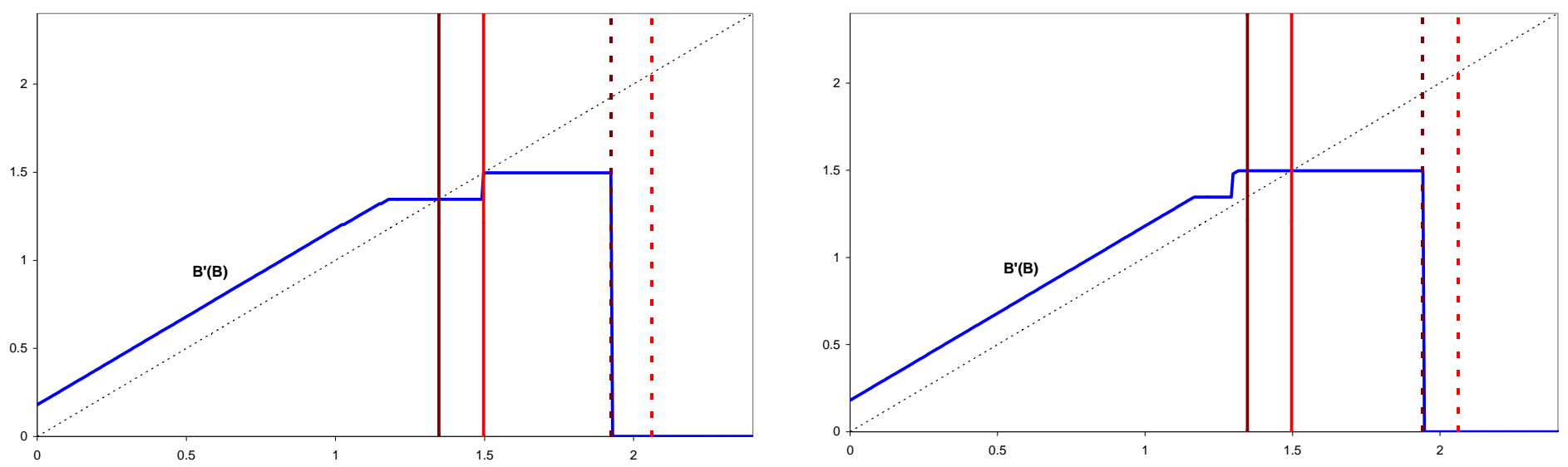

In the left panel of Figure 12 we show the changes when the crisis is much more severe than in the benchmark. The output loss in bad times is 30\% relative to good times. Notice that the lower and upper bound in bad times shift to the left relative to the benchmark scenario. The optimal policy generates three steady states. In the safe zone the optimal policy prescribes running up the debt. In the crisis zone there is a steady state between the two thresholds below which it is optimal to run down and above which it is optimal to run up until the safe zone if there is recovery. Above that there is a small crisis zone where it is optimal to run down.

In the right upper panel of Figure 12 we show the changes when the penalty upon default is very large (50\% of output). As usual if the economy is in the safe zone then the optimal policy is to run up until it hits the lower threshold. If the economy is in the crisis zone then there are three areas. First (for relatively low debt) run debt down, next keep it constant, and if debt is relatively high run it up until the steady state where you are indifferent between defaulting or not.

Finally in the bottom two panels of Figure 12 we examine the impact of increasing the probability of a recovery. If the probability is 95\% (left) then both lower debt thresholds are steady states, and eventually as the probability gets sufficiently close to $100 \%$ (right) the steady state is the lower debt threshold in good times. 


\section{References}

Arellano, C. (2008), “Default Risk and Income Fluctuations in Emerging Economies,” American Economic Review, 98, 690-712.

Calvo, G. (1988), “Servicing the Public Debt: The Role of Expectations,” American Economic Review, 78, 647-661.

Chamley, C. P. and B. Pinto (2011), "Why Bailouts Tend Not To Work: An Example Motivated by Greece 2010,” The Economists’ Voice, 8, article 3.

Cole, H. L. and T. J. Kehoe (1996), “A Self-Fulfilling Model of Mexico’s 1994-1995 Debt Crisis,” Journal of International Economics, 41, 309-330.

Cole, H. L. and T. J. Kehoe (2000), “Self-Fulfilling Debt Crises,” Review of Economic Studies, 67, 91-116.

Morris, S. and H. S. Shin (1998), "Unique Equilibrium in a Model of Self-Fulfilling Currency Attacks,” American Economic Review, 88, 587-596.

Reinhart, C. M. and K. S. Rogoff (2009), This Time is Different: Eight Centuries of Financial Follies, Princeton University Press. 


\section{Appendix: The algorithm for computing an equilibrium in the general model}

The algorithm computes the four debt thresholds, the value function, and the policy function.

1. Compute the value function $V\left(B, a, z_{-1}, \zeta\right)$ of being in the default state, where $B=0$ and $Z_{-1}=1$ :

The value function in normal times, where $a=1$, is

$$
V(0,1,1, \zeta)=u[(1-\theta) Z y, \theta Z y]+\beta V(0,1,1, \zeta)
$$

which is just a constant:

$$
V(0,1,1, \zeta)=\frac{1}{1-\beta} u[(1-\theta) Z y, \theta Z y]
$$

Similarly, in a recession, where $a=0$,

$$
V(0,0,1, \zeta)=u[(1-\theta) A Z y, \theta A Z y]+\beta p V(0,1,1, \zeta)+\beta(1-p) V(0,0,1, \zeta),
$$

which is also just a constant:

$$
V(0,0,1, \zeta)=\frac{1}{1-\beta(1-p)} u[(1-\theta) A Z y, \theta A Z y]+\frac{\beta p}{(1-\beta(1-p))(1-\beta)} u[(1-\theta) Z y, \theta Z y]
$$

Notice that theses values are independent of the sunspot $\zeta$.

2. Guess initial values for the thresholds $\bar{b}(0), \bar{b}(1), \bar{B}(0), \bar{B}(1)$, where $\bar{b}(0)<\bar{b}(1)<\bar{B}(0)<\bar{B}(1)$. (We can modify the algorithm to calculate an equilibrium where $\bar{b}(0)<\bar{B}(0)<\bar{b}(1)<\bar{B}(1)$.)

3. Perform value function iteration on a finite grid of values for debt to compute the value function in normal times, where $a=1$ :

Guess an initial value for the value functions if we are in good times and the government has not defaulted in the past: $\tilde{V}(B, 1,0, \zeta)$. Then:

3.1. For low values of initial debt $B \leq \bar{b}(1)$ : 
$\forall \zeta$ the value function is: $V(B, 1,0, \zeta)=\max \left\{V_{1}(B, 1,0, \zeta), V_{2}(B, 1,0, \zeta)\right\}$, where

$V_{1}(), V_{2}()$ are defined as:

$$
\begin{gathered}
V_{1}(B, 1,0, \zeta)=\max _{B^{\prime} \leq b(1)}\left\{u\left[(1-\theta) y, \theta y+\beta B^{\prime}-B\right]+\beta \tilde{V}\left(B^{\prime}, 1,0, \zeta^{\prime}\right)\right\} . \\
V_{2}(B, 1,0, \zeta)=\max _{B^{\prime} \in(\bar{b}(1), \bar{B}(1)]}\left\{u\left[(1-\theta) y, \theta y+\beta(1-\pi) B^{\prime}-B\right]+\beta(1-\pi) \tilde{V}\left(B^{\prime}, 1,0, \zeta^{\prime}\right)+\beta \pi V\left(0,1,1, \zeta^{\prime}\right)\right\}
\end{gathered}
$$

3.2. For intermediate values of initial debt $B \in(\bar{b}(1), \bar{B}(1)]$ :

If $\zeta>1-\pi$ then $V(B, 1,0, \zeta)=V(0,1,1, \zeta)$.

Else if $\zeta \leq 1-\pi$ then $V(B, 1,0, \zeta)=\max \left\{V_{1}(B, 1,0, \zeta), V_{2}(B, 1,0, \zeta)\right\}$, with $V_{1}(), V_{2}()$ defined as above.

3.3. For high values of initial debt $B>\bar{B}(1): V(B, 1,0, \zeta)=V(0,1,1, \zeta), \forall \zeta$.

3.4. If $\max _{B, \zeta}|V(B, 1,0, \zeta)-\tilde{V}(B, 1,0, \zeta)|>\varepsilon$, then $\tilde{V}(B, 1,0, \zeta)=V(B, 1,0, \zeta)$ and go to 3.1.

Else, go to 4.

4. Perform value function iteration on a finite grid of values for debt to compute the value function in a recession, where $a=0$.

Guess an initial value for the value functions if we are in a recession and the government has not defaulted in the past: $\tilde{V}(B, 0,0, \zeta)$. Then:

4.1. For low values of initial debt, where $B \leq \bar{b}(0)$, the value function is:

$$
V(B, 0,0, \zeta)=\max \left\{V_{1}(B, 0,0, \zeta), V_{2}(B, 0,0, \zeta), V_{3}(B, 0,0, \zeta), V_{4}(B, 0,0, \zeta)\right\},
$$

where $V_{1}, V_{2}, V_{3}, V_{4}$ are defined as

$$
\begin{gathered}
V_{1}(B, 0,0, \zeta)=\max _{B^{\prime} \leq b(0)}\left\{\begin{array}{c}
u\left[(1-\theta) A y, \theta A y+\beta B^{\prime}-B\right] \\
+\beta p V\left(B^{\prime}, 1,0, \zeta^{\prime}\right)+\beta(1-p) \tilde{V}\left(B^{\prime}, 0,0, \zeta^{\prime}\right)
\end{array}\right\} \\
V_{2}(B, 0,0, \zeta)=\max _{B^{\prime} \in(\bar{b}(0), \bar{b}(1)]}\left\{\begin{array}{l}
u\left[(1-\theta) A y, \theta A y+\beta(p+(1-p)(1-\pi)) B^{\prime}-B\right] \\
+\beta p V\left(B^{\prime}, 1,0, \zeta^{\prime}\right)+\beta(1-p) \pi V\left(0,0,1, \zeta^{\prime}\right)+\beta(1-p)(1-\pi) \tilde{V}\left(B^{\prime}, 0,0, \zeta^{\prime}\right)
\end{array}\right\}
\end{gathered}
$$




$$
\begin{gathered}
V_{3}(B, 0,0, \zeta)=\max _{B^{\prime} \in(\bar{b}(1), \bar{B}(0)]}\left\{\begin{array}{l}
u\left[(1-\theta) A y, \theta A y+\beta(1-\pi) B^{\prime}-B\right] \\
+\beta p \pi V\left(0,1,1, \zeta^{\prime}\right)+\beta p(1-\pi) \tilde{V}\left(B^{\prime}, 1,0, \zeta^{\prime}\right) \\
+\beta(1-p) \pi V\left(0,0,1, \zeta^{\prime}\right)+\beta(1-p)(1-\pi) \tilde{V}\left(B^{\prime}, 0,0, \zeta^{\prime}\right)
\end{array}\right\} \\
V_{4}(B, 0,0, \zeta)=\max _{B^{\prime} \in(\bar{B}(0), \bar{B}(1)]}\left\{\begin{array}{l}
u\left[(1-\theta) A y, \theta A y+\beta p(1-\pi) B^{\prime}-B\right]+ \\
+\beta p \pi V\left(0,1,1, \zeta^{\prime}\right)+\beta p(1-\pi) V\left(B^{\prime}, 1,0, \zeta^{\prime}\right)+\beta(1-p) V\left(0,0,1, \zeta^{\prime}\right)
\end{array}\right\}
\end{gathered}
$$

4.1. For intermediate values of initial debt $B \in(\bar{b}(0), \bar{B}(0)]$ :

If $\zeta>1-\pi$ then $V(B, 0,0, \zeta)=V(0,0,1, \zeta)$.

Else if $\zeta \leq 1-\pi$ then

$$
\begin{aligned}
& V(B, 0,0, \zeta)=\max \left\{V_{1}(B, 0,0, \zeta), V_{2}(B, 0,0, \zeta), V_{3}(B, 0,0, \zeta), V_{4}(B, 0,0, \zeta)\right\} \text {, with } \\
& V_{1}(), V_{2}(), V_{3}(), V_{4}() \text { defined as above. }
\end{aligned}
$$

4.2. For high values of initial debt $B>\bar{B}(0)$ :

$V(B, 0,0, \zeta)=V(0,0,1, \zeta), \forall \zeta$

4.4. If $\max _{B, \zeta}|V(B, 0,0, \zeta)-\tilde{V}(B, 0,0, \zeta)|>\varepsilon$, then $\tilde{V}(B, 0,0, \zeta)=V(B, 0,0, \zeta)$ and go to 4.1. Else, go to 5 .

5. Update the threshold values.

5.1. Choose $\bar{b}_{\text {new }}(0)$ to be the highest point in the debt grid for which the following condition is satisfied:

$\{u[(1-\theta) A y, \theta A y-B]+\beta p V(0,1,0,0)+\beta(1-p) V(0,0,0,0)\} \geq V(0,0,1, \zeta)$

5.2. Choose $\bar{b}_{\text {new }}(1)$ to be the highest point in the debt grid for which the following condition is satisfied: 
$\{u[(1-\theta) y, \theta y-B]+\beta V(0,1,0,0)\} \geq V(0,1,1, \zeta)$

5.3. Choose $\bar{B}_{\text {new }}(0)$ to be the highest point in the debt grid for which the following condition is satisfied:

$V(B, 0,0,0) \geq\left\{u\left[(1-\theta) Z A y, \theta Z A y+q\left(B^{\prime}\right) B^{\prime}(B, 0,0,0)\right]+\beta p V\left(0,1,1, \zeta^{\prime}\right)+\beta(1-p) V\left(0,0,1, \zeta^{\prime}\right)\right\}$

where $q\left(B^{\prime}\right)=\beta(1-\pi)$ if $B^{\prime}(B, 0,0,0) \leq \bar{B}(0)$ and $q\left(B^{\prime}\right)=\beta p(1-\pi)$ if $B^{\prime}(B, 0,0,0)>\bar{B}(0)$.

5.4. Choose $\bar{B}_{\text {new }}(1)$ to be the highest point in the debt grid for which the following condition is satisfied:

$V(B, 1,0,0) \geq\left\{u\left[(1-\theta) Z y, \theta Z y+\beta(1-\pi) B^{\prime}(B, 1,0,0)\right]+\beta V\left(0,1,1, \zeta^{\prime}\right)\right\}$

5.5. If $\left|\bar{b}_{\text {new }}(0)-\bar{b}(0)\right|>\varepsilon$ or $\left|\bar{b}_{\text {new }}(1)-\bar{b}(1)\right|>\varepsilon$ or $\left|\bar{B}_{\text {new }}(0)-\bar{B}(0)\right|>\varepsilon$ or $\left|\bar{B}_{\text {new }}(1)-\bar{B}(1)\right|>\varepsilon$, then $\bar{b}(0)=\bar{b}_{\text {new }}(0), \bar{b}(1)=\bar{b}_{\text {new }}(1), \bar{B}(0)=\bar{B}_{\text {new }}(0), \bar{B}(1)=\bar{B}_{\text {new }}(1)$ and go to 3. Else, exit. 